
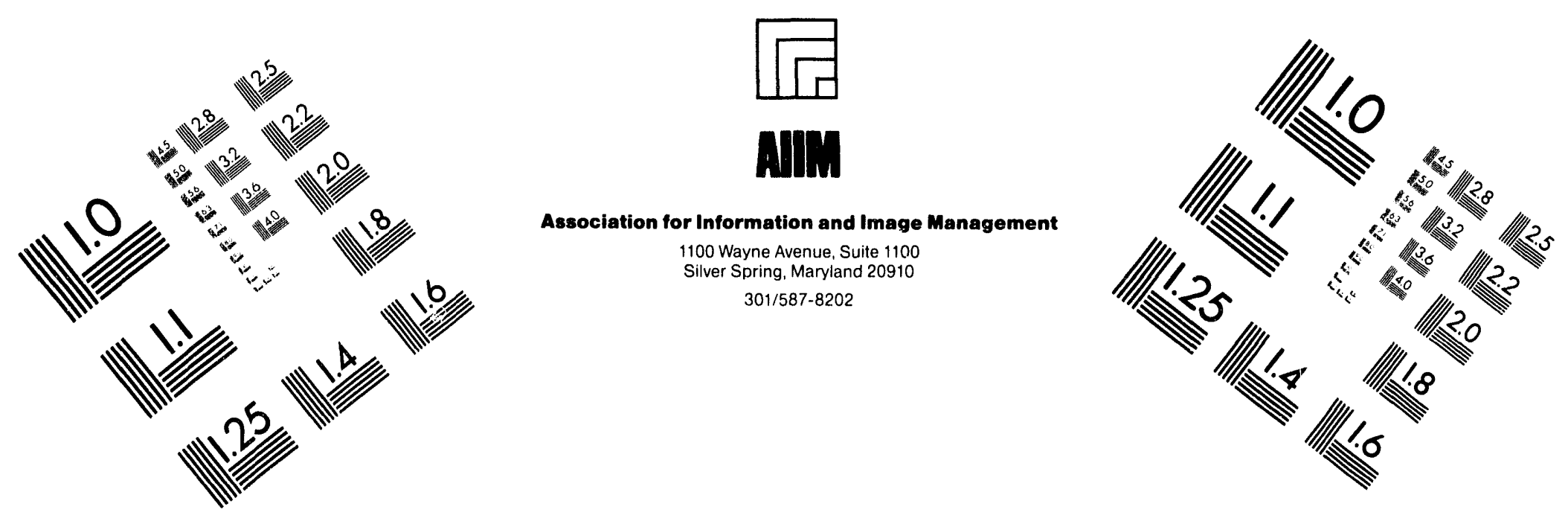

\title{
Centimeter
}

$\begin{array}{llllllllllllllll}1 & 2 & 3 & 4 & 5 & 6 & 7 & 8 & 9 & 10 & 11 & 12 & 13 & 14 & 15 & \mathrm{~mm}\end{array}$

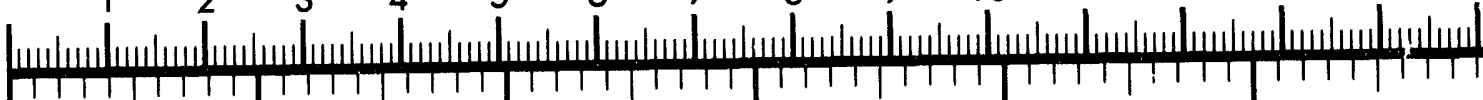

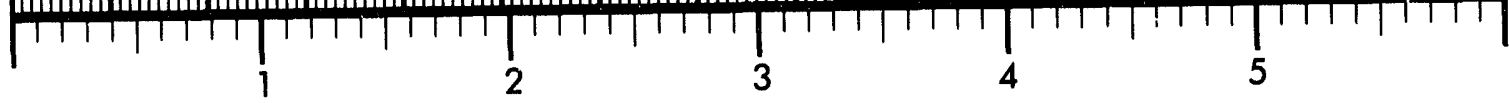
Inches
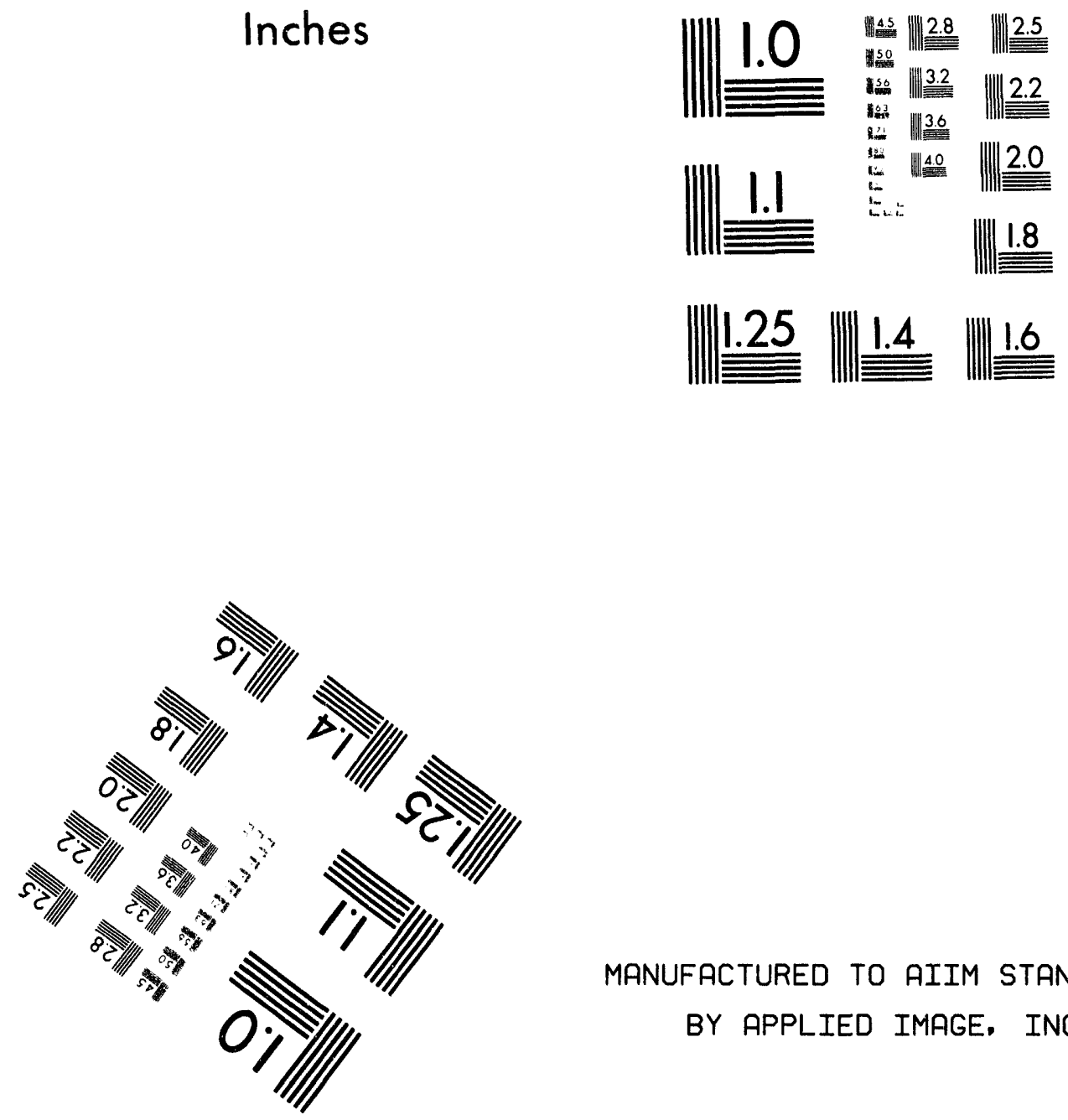

MANUFACTURED TO AIIM STANDARDS BY APPLIED IMAGE, INC.

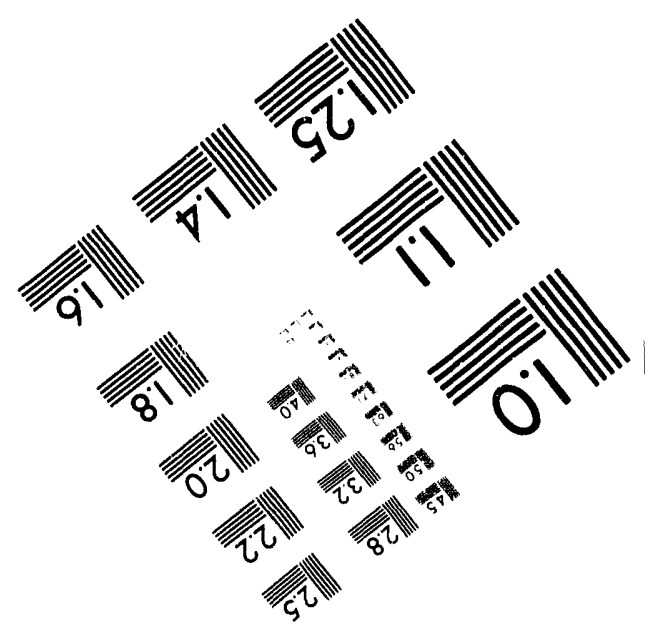



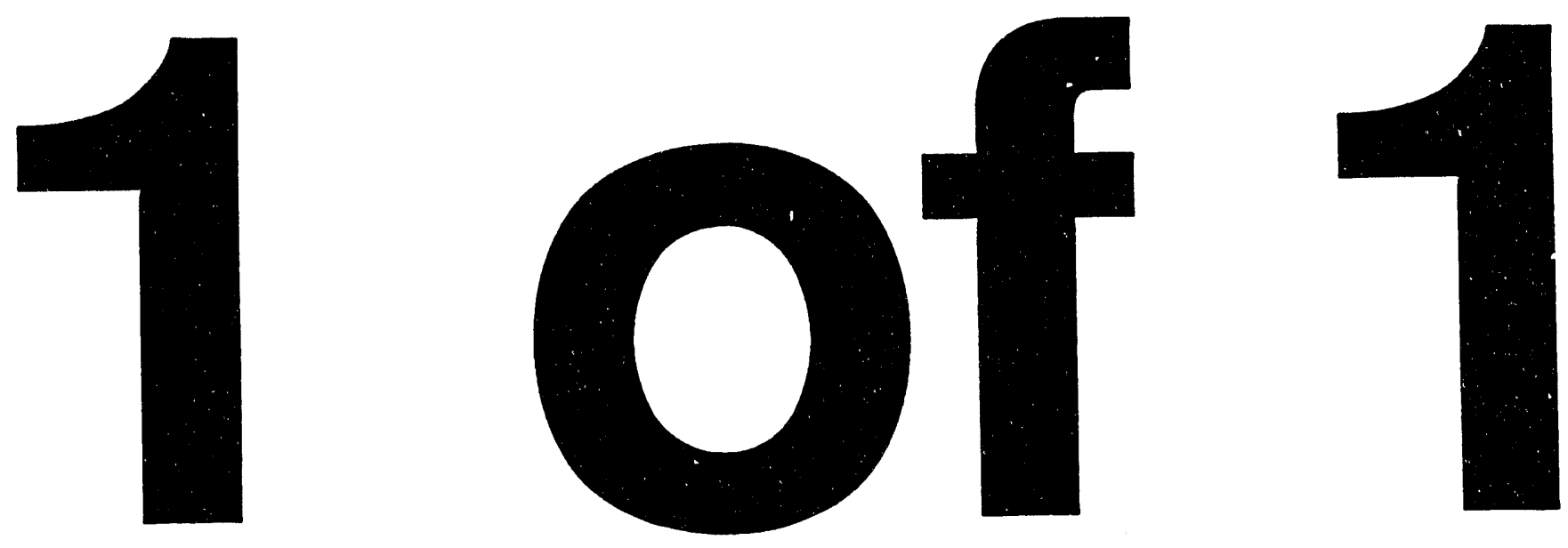
NUREG/CR-6177

ANL-94/2

\section{Assessment of Thermal \\ Embrittlement of \\ Cast Stainless Steels}

Manuscript Completed: December 1993

Date Published: May 1994

Prepared by

O. K. Chopra, W. J. Shack

Argonne National Laboratory

9700 South Cass Avenue

Argonne, IL 60439

Prepared for

Office of Nuclear Reactor Regulation

U.S. Nuclear Regulatory Commission

Washington, DC 20555-0001

NRC FIN L2424 


\title{
Assessment of Thermal Embrittlement of Cast Stainless Steels
}

by

\author{
O. K. Chopra and W. J. Shack
}

\begin{abstract}
A procedure and correlations are presented for assessing thermal embrittlement and predicting Charpy-impact energy and fracture toughness J-R curve of cast stainless steel components under light water reactor operating conditions from known material information. The "saturation" impact strength and fracture toughness of a specific cast stainless steel, i.e., the minimum value that would be achieved for the material after long-term service, is estimated from the chemical composition of the steel. Fracture properties as a function of time and temperature of reactor service are estimated from the kinetics of embrittlement, which are also determined from chemical composition. A common "predicted lower-bound" J-R curve for cast stainless steels of unknown chemical composition is also defined for a given grade of steel, ferrite content, and temperature. Examples of estimating fracture toughness of cast stainless steel components during reactor service are presented.
\end{abstract}


Contents

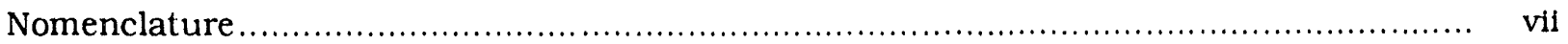

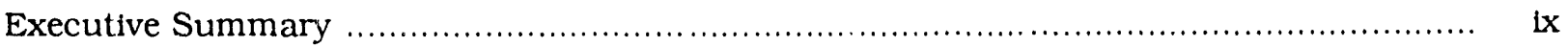

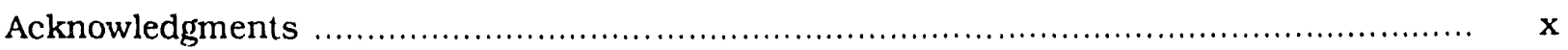

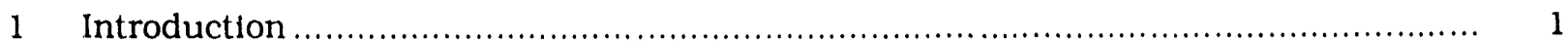

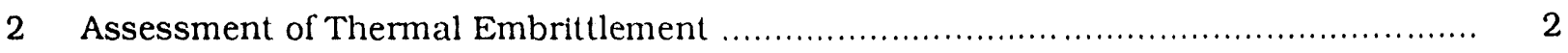

2.1 Estimate for Steels of Unknown Composition: Lower-Bound Values ................ 4

2.2 Estimate for Steels of Known Composition and Unknown Service History:

Saturation Values ........................................................................... 4

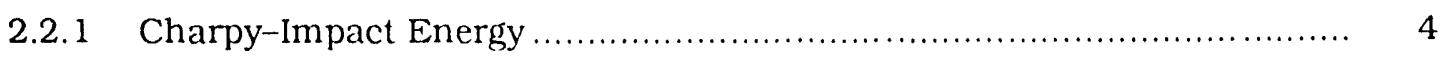

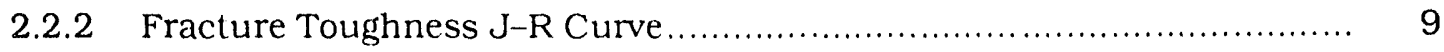

2.3 Estimate for Steels of Known Composition and Service History:

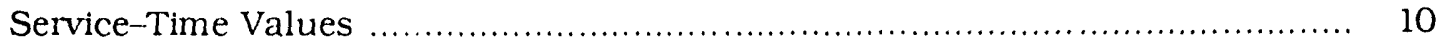

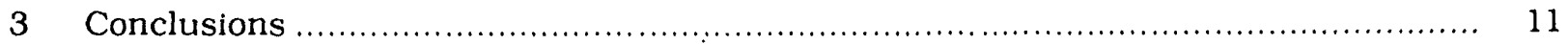

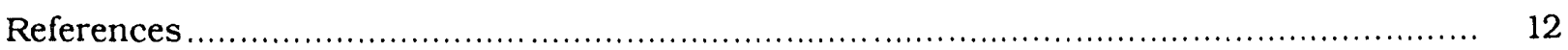

Appendix: Estimation of Fracture Properties of Cast SSs .................................. A-1 


\section{List of Figures}

1. Flow diagram for estimating mechanical properties of aged cast SSs in LWR systems

2. Lower-bound $\mathrm{J}-\mathrm{R}$ curves at $\mathrm{RT}$ and $290^{\circ} \mathrm{C}$ for static-cast SSs with ferrite contents $>15,10-15$, or $<10 \%$

3. Lower-bound J-R curves at RT and $290^{\circ} \mathrm{C}$ for centrifugally cast SSs with ferrite contents $>15,10-15$, or $<10 \%$.

A-1. Estimation scheme for Example 1 A-1

A-2. Estimation scheme for Example 2 A-3

A-3. Estimation scheme for Example 3 A-5

A-4. Estimation scheme for Example 4

\section{List of Tables}

1. Values of coefficient $\mathrm{C}$ and exponent $\mathrm{n}$ for lower-bound $\mathrm{J}-\mathrm{R}$ curve for cast SSs .........

2. Values of constants in Eq. 13 for estimating power-law J-R curve for cast SSs.........

3. Values of constants in Eq. 14 for estimating exponent $n$ of power-law J-R curve for cast SSs 
C Coefficient of the power-law J-R curve.

$\mathrm{Cr}_{\text {eq }}$ Chromium equivalent for a material (wt.\%).

$\mathrm{C}_{\mathrm{V}} \quad$ Room-temperature "normalized" Charpy-impact energy, i.e., Charpy-impact energy per unit fracture area, at any given service and aging time $\left(\mathrm{J} / \mathrm{cm}^{2}\right)$. The fracture area for a standard Charpy V-notch specimen (ASTM Specification E 23) is $0.8 \mathrm{~cm}^{2}$. Divide the value of impact energy in $J$ by 0.8 to obtain "normalized" impact energy.

$\mathrm{C}_{\text {Vint }}$ Initial room-temperature "normalized" Charpy-impact energy of a material, i.e., unaged material $\left(\mathrm{J} / \mathrm{cm}^{2}\right)$.

CVsat Room-temperature "normalized" Charpy-impact energy of a material at saturation, i.e., the minimum impact energy that would be achieved for the material after longterm service $\left(\mathrm{J} / \mathrm{cm}^{2}\right)$.

CMTR Certified material test record.

$\mathrm{J}_{\mathrm{d}} \quad$ Deformation $\mathrm{J}$ per ASTM Specification E $813-85$ or E $1152-87\left(\mathrm{~kJ} / \mathrm{m}^{2}\right)$.

n Exponent of the power-law J-R curve.

$\mathrm{Ni}_{\text {eq }} \quad$ Nickel equivalent for a material (wt.\%).

P Aging parameter, i.e., the log of the time of aging at $400^{\circ} \mathrm{C}$.

Q Activation energy for the process of thermal embrittlement $(\mathrm{kJ} / \mathrm{mole})$.

$\mathrm{t}$ Service or aging time (h).

$\mathrm{T}_{\mathrm{S}} \quad$ Service or aging temperature $\left({ }^{\circ} \mathrm{C}\right)$.

$\alpha \quad$ Shape factor of the curve for the change in room-temperature Charpy-impact energy with time and temperature of aging.

$\beta \quad$ Half the maximum change in room-temperature Charpy-impact energy.

$\delta_{c} \quad$ Ferrite content calculated from the chemical composition of a material (\%).

$\Delta a \quad$ Crack extension (mm).

$\Phi \quad$ Material parameter.

$\theta \quad$ Aging behavior at $400^{\circ} \mathrm{C}$, i.e., the log of the time to achieve $\beta$ reduction in impact energy at $400^{\circ} \mathrm{C}$.

$\sigma \quad$ Standard deviation for the fit to a data set.

In this report, all values of impact energy are considered to be for a standard Charpy-Vnotch specimen per ASTM Specification E 23), i.e., $10 \times 10-\mathrm{mm}$ cross section and 2-mm $\mathrm{V}$ notch. Impact energies obtained on subsize specimens should be normalized with respect to the actual cross-sectional area and appropriate correction factors should be applied to account for size effects. Similarly, impact energy from other standards, e.g., U-notch specimen, should be converted to a Charpy-V-notch value by appropi iate correlations. 
SI units of measurements have been used in this report. Conversion factors for measurements in British units are as follows:

$\begin{array}{lll}\text { To convert from } & \text { to } & \text { multiply by } \\ \text { in. } & \mathrm{mm} & 25.4 \\ \mathrm{~J}^{*} & \mathrm{ft} \cdot \mathrm{lb} & 0.7376 \\ \mathrm{~kJ} / \mathrm{m}^{2} & \text { in.-lb/in. }{ }^{2} & 5.71015 \\ \mathrm{~kJ} / \mathrm{mole} & \mathrm{kcal} / \text { mole } & 0.239\end{array}$

${ }^{*}$ When impact energy is expressed in $\mathrm{J} / \mathrm{cm}^{2}$, first multiply by 0.8 to obtain impact energy of a standard Charpy $\mathrm{V}$-notch specimen in $\mathrm{J}$. 


\section{Executive Summary}

Cast stainless steels used in valve bodies, pump casings, piping, and other components in coolant systems of light water reactors (LWRs) suffer a loss in fracture toughness due to thermal aging after many years of service at temperatures in the range of $280-320^{\circ} \mathrm{C}\left(\approx 535-610^{\circ} \mathrm{F}\right)$. Thermal aging of cast stainless steels at these temperatures causes an increase in hardness and tensile strength and a decrease in ductility, impact strength, and fracture toughness of the material. The Charpy transition curve shifts to higher temperatures. Investigations at Argonne National Laboratory (ANL) and elsewhere have shown that thermal embrittlement of cast stainless steel components can occur during reactor operation. Therefore, an assessment of mechanical-property degradation due to thermal embrittlement is required to evaluate the performance of cast stainless steel components during prolonged exposure to service temperatures.

This report presents a procedure and correlations for predicting Charpy-impact energy and fracture toughness $J-R$ curve of aged cast stainless steels (ASTM A 351) from known material information. Mechanical properties of a specific cast stainless steel are estimated from the extent and kinetics of thermal embrittlement. Embrittlement of cast stainless steels is characterized in terms of room-temperature Charpy-impact energy. The extent or degree of thermal embrittlement at "saturation," i.e., the minimum impact energy that can be achieved for the material after long-term aging, is determined from chemical composition of the steel. Charpy-impact energy as a function of time and temperature of reactor service is estimated from the kinetics of thermal embrittlement, which is also determined from the chemical composition. The initial impact energy of the unaged steel is required for these estimations. The fracture toughness $\mathrm{J}-\mathrm{R}$ curve for the material is then obtained from correlations between room-temperature Charpy-impact energy and fracture toughness parameters. A common "predicted lower-bound" J-R curve for cast stainless steels with unknown chemical composition is also defined for a given grade of steel, range of ferrite contents, and temperature. Examples of estimating mechanical properties of cast stainless steel components during reactor service are presented. 


\section{Acknowledgments}

This work was supported by the License Renewal Project Directorate, Office of Nuclear Reactor Regulation, U.S. Nuclear Regulatory Commission (NRC), under FIN L2424; Program Manager: D. Jackson. The mechanical-property data base and the methodology and correlations for estimating fracture properties of aged cast stainless steels have been developed over a period of $10 \mathrm{yr}$ as part of a program entitled "Long-Term Embrittlement of Cast Stainless Steels in LWR Systems," sponsored by the Office of Nuclear Regulatory Research, U.S. NRC. under FIN A2243 Program Manager: Joe Muscara. The authors are thankful to Sam Lee and Tom Kassner for their helpful discussions. 


\section{Introduction}

Cast stainless steels (SSs) used in light water reactor (LWR) systems for primary pressureboundary components such as valve bodies, pump casings, and primary coolant piping are susceptible to thermal embrittlement at reactor operating temperatures, i.e., $280-320^{\circ} \mathrm{C}(536-$ $608^{\circ} \mathrm{F}$ ). Thermal aging of cast SS at these temperatures increases hardness and tensile strength and decreases ductility, impact strength, and fracture toughness of the material. The Charpy transition curve shifts to higher temperatures. Investigations at Argonne National Laboratory $(\mathrm{ANL})^{1-3}$ have shown that thermal embrittlement of cast SS components (i.e., ASTM Specification A-351 grades ${ }^{*} \mathrm{CF}-3, \mathrm{CF}-3 \mathrm{~A}, \mathrm{CF}-8, \mathrm{CF}-8 \mathrm{~A}$, and $\mathrm{CF}-8 \mathrm{M}$ ) can occur within the design lifetime of nuclear reactors. Cast SS components with 10-15\% ferrite may show significant thermal embrittlement. For example, the hot-leg elbow from the Ringhals 2 reactor showed poor fracture properties, e.g., room-temperature (RT) Charpy-impact energy of $36 \mathrm{~J}$ $(\approx 26 \mathrm{ft} \cdot \mathrm{lb})$ and fracture toughness $J_{\text {IC }}$ values of $150-330 \mathrm{~kJ} / \mathrm{m}^{2}\left(856-1884 \mathrm{in} \cdot \mathrm{lb} / \mathrm{in}^{2}\right) .3,4$ The hot-leg elbow, constructed from $\mathrm{CF}-8 \mathrm{M}$ steel, was in service for $\approx 15 \mathrm{yr}$ at $350^{\circ} \mathrm{C}$ and contained $\approx 12 \%$ ferrite.

An assessment of mechanical-property degradation due to thermal embrittlement is therefore required to evaluate the performance of cast SS components during prolonged exposure to service temperatures, because rupture of the primary pressure boundary could lead to a loss-of-coolant accident and possible exposure of the public to radiation. A procedure and correlations have been developed at ANL for estimating mechanical properties of cast SS components under LWR operating conditions from material information readily avallable in certified material test records (CMTRs). The procedure and correlations were published in NUREG/CR4513, ANL-90/42 (June 1991). ${ }^{5}$ Mechanical properties of a specific cast SS are estimated from the extent and kinetics of thermal embrittlement. Embrittlement of cast SSs is characterized in terms of RT Charpy-impact energy. The extent of therrnal embrittlement at "saturation," i.e., the minimum impact energy that can be achieved for a steel after long-term aging, is determined from chemical composition of the steel. Charpy-impact energy as a function of time and temperature of reactor service is estimated from the kinetics of thermal embrittlement, which is also determined from the chemical composition. The fracture toughness $\mathrm{J}-\mathrm{R}$ curve for the steel is then obtained from correlations between RT Charpy-impact energy and fracture toughness parameters. A common "predicted lower-bound" J-R curve for cast SSs of unknown chemical composition is also defined for a given grade of steel, ferrite content, and temperature.

This report presents a revised version of the procedure and correlations for estimating Charpy-impact and fracture toughness properties of cast SS components under LWR operating conditions. The differences between the correlations described in this report and those presented earlier are as follows:

- The correlations have been optimized by using a larger data base (e.g., $\approx 80$ compositions of cast SS) and mechanical-property results on materials that were aged up to $\approx 58,000 \mathrm{~h}$ at $290-350^{\circ} \mathrm{C}\left(554-662^{\circ} \mathrm{F}\right)$. The earlier correlations were based on $\approx 45$ compositions of cast SS and aging times up to $30,000 \mathrm{~h}$. For the 80 compositions of cast SSs used in this

\footnotetext{
*In this report, grades $\mathrm{CF}-3 \mathrm{~A}$ and $\mathrm{CF}-8 \mathrm{~A}$ are considered equivalent to $\mathrm{CF}-3$ and $\mathrm{CF}-8$, respectively. The $\mathrm{A}$ designation represents high tensile strength. The chemical composition of $\mathrm{CF}-3 \mathrm{~A}$ and $\mathrm{CF}-8 \mathrm{~A}$ are further restricted within the composition limits of $\mathrm{CF}-3$ and $\mathrm{CF}-8$, respectively. to obtain a ferrite/austenite ratio that results in higher ultimate and yield strengths.
} 
study, estimates based on the old correlations yield conservative values of fracture toughness.

- The saturation RT impact energy $\mathrm{C}_{\mathrm{Vsa}}$ is estimated from two different correlations. For most heats, the two methods give comparable estimates. For a few heats, however, one or the other set of expressions gives more accurate estimates. It is likely that minor differences in the composition and microstructure of the ferrite caused by differences in production heat treatment and possibly the casting process influence $\mathrm{C}_{V \text { sat }}$ values. These factors cannot be quantified from the present data base. To ensure that the estimates are either accurate or conservative for all heats of cast SS within ASTM Specification A 351, the lower of the two estimated values is used for estimating the fracture properties.

- Different correlations are used to estimate the saturation RT impact energy CVsat for $\mathrm{CF}-8 \mathrm{M}$ steels with $<10$ and $\geq 10 \mathrm{wt} . \% \mathrm{Ni}$.

- Separate correlations are given for estimating fracture toughness J-R curves for staticand centrifugally cast SSs. Also, the correlation for estimating exponent $\mathbf{n}$ of the powerlaw $\mathrm{J}-\mathrm{R}$ curve has been modified.

- For $\mathrm{CF}-3$ and $\mathrm{CF}-8$ steels, the expression for estimating the activation energy for thermal embrittlement has been modified. The effect of Mo and MIn content has been omitted and the effect of $\mathrm{C}$ content has been added in the updated expression.

The criteria used in developing these correlations ensure that the estimated mechanical properties are adequately conservative for cast SSs deiined by ASTM Specification A 351. ${ }^{*}$ The correlations do not consider the effects of metallurgical differences that may arise from differences in production heat treatment or casting processes and therefore may be overly conservative for some steels. Mechanical properties are expressed in SI units (see Nomenclature for units of measure and for conversion factors for British units).

\section{Assessment of Thermal Embrittlement}

Mechanical properties of cast SSs during reactor service are estimated from the extent of thermal embrittlement for the material. The extent of thermal embrittlement is characterized by RT "normalized" Charpy-impact energy. A correlation for the extent of embrittlement at "saturation," i.e., the minimum impact energy that would be achieved for the material after long-term aging, is given in terms of chemical composition. Extent of thermal embrittlement as a function of time and temperature of reactor service is estimated from the extent of embrittlement at saturation and from correlations that describe the kinetics of embrittlement, which are also given in terms of the chemical composition of the steel. The fracture toughness J-R curve for the material is then obtained from the correlation between fracture toughness parameters and the RT Charpy-impact energy used to characterize the extent of thermal embrittlement.

\footnotetext{
*These correlations may yield nonconservative estimates of fracture toughness $\mathrm{J}-\mathrm{R}$ curve for a few compositions of static-cast CF-8M steel that are very sensitive to thermal aging, i.e., those compositions of static-cast SS for which the estimated value of $\mathrm{C}_{\mathrm{Vsat}}$ is $<25 \mathrm{~J} / \mathrm{cm}^{2}(<15 \mathrm{ft} \cdot \mathrm{lb})$. These compositions should contain $\geq 25 \%$ ferrite. The existing data are not adequate to accurately establish the correlations between room-temperature Charpyimpact energy and fracture toughness parameters for estimated values of $C_{V s a t}<25 \mathrm{~J} / \mathrm{cm}^{2}$.
} 


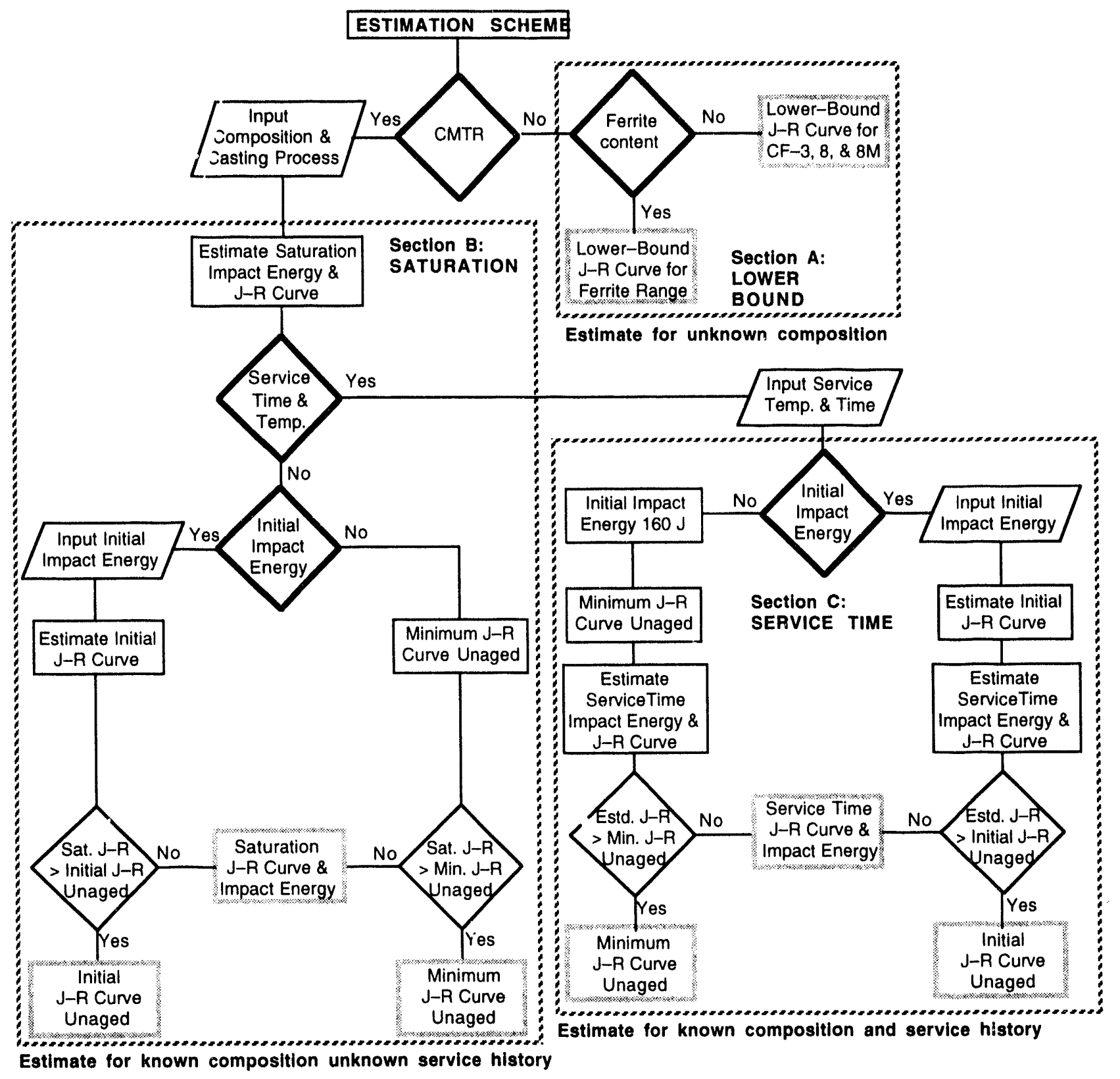

Figure 1. Flow diagram for estimating mechanical properties of aged cast SSs in LWR systems

A flow diagram for estimating Charpy-impact energy and fracture toughness J-R curve of cast SS components is shown in Fig. 1. The estimation scheme is divided into three sections on the basis of available information. In Section A, "predicted lower-bound" fracture toughness is defined for $\mathrm{CF}-3, \mathrm{CF}-8$, and $\mathrm{CF}-8 \mathrm{M}$ steels of unknown composition. When the ferrite content of the steel is known, a different lower-bound fracture toughness is defined for steels containing $<10 \%, 10-15 \%$, or $>15 \%$ ferrite. Sections B and C present procedures for estimating mechanical properties when a CMTR is available. Section B describes the estimation of "saturation" impact energy and fracture toughness J-R curve. The only information needed for these estimations is the chemical composition of the material. 
The present correlations account for the degradation of mechanical properties due to thermal aging. They do not explicitly consider the initial fracture properties of the unaged material. It is possible that the estimations of saturation fracture toughness based on chemical composition are higher than the fracture toughness of the unaged material. Some cast SSs are inherently weak and may have poor fracture properties in the unaged condition. When information is available on either the initial fracture toughness of a material or the initial RT Charpy-impact energy for estimating fracture toughness, and when the J-R curve estimated from the chemical composition is higher than the initial fracture toughness of unaged material, the latter is used as the situration J-R curve of the material. Such cast SSs are relatively insensitive to thermal aging, and the fracture toughness of the material would not change during reactor service. Furthermore, when no information is available on the initial fracture toughness of a material, the minimum fracture toughness of unaged cast SSs is used as a upper bound for the estimated fracture toughness; i.e., when the J-R curve estimated from the chemical composition is higher than the minimum fracture toughness of unaged cast SSs, the latter is used as the saturation $\mathrm{J}-\mathrm{R}$ curve of a material.

Estimation of mechanical properties at any given time and temperature of service, i.e., service-time properties, is described in Section C. The initial impact energy of the unaged material is required for these estimations. If not known, the initial impact energy can be assumed to be $200 \mathrm{~J} / \mathrm{cm}^{2}$. However, similar to Section B, initial fracture toughness of the unaged material or the minimum fracture toughness of unaged cast SSs is used as a upper bound for the estimations.

\subsection{Estimate for Steels of Unknown Composition: Lower-Bound Values}

For cast SSs of unknown chemical composition within ASTM Specification A 351, the lower-bound fracture toughness $J-R$ curve is defined for a given method of casting, material grade, and temperature. The $J-R$ curve is expressed by the power-law relation $J_{d}=C(\Delta a)^{n}$, where $J_{d}$ is deformation $J$ per ASTM Specifications E 813-85 and E 1152-87, $\Delta$ a is the crack extension, and $\mathrm{C}$ and $\mathrm{n}$ are constants. The lower-bound curve is based on the "worst case" material condition, e.g., $>20 \%$ ferrite content. The cast SSs used in the U.S. nuclear industry generally contain $<15 \%$ ferrite. The lower-bound fracture properties for a specific casting method and grade of steel may therefore be very conservative for most steels. More realistic estimates of lower-bound properties are obtained if the ferrite content of the steel is known. The ferrite content of a cast SS component can be measured in the field with a ferrite scope. The lower-bound J-R curves at RT and $290^{\circ} \mathrm{C}$ for static- and centrifugally cast $\mathrm{CF}-3, \mathrm{CF}-8$, and $\mathrm{CF}-8 \mathrm{M}$ steels with $>15 \%, 10-15 \%$, and $<10 \%$ ferrite are shown in Figs. 2 and 3 and the values of the coefficient $\mathrm{C}$ and exponent $\mathrm{n}$ for the $\mathrm{J}-\mathrm{R}$ curves are given in Table 1 .

\subsection{Estimate for Steels of Known Composition and Unknown Service History: Saturation Values}

\subsubsection{Charpy-Impact Energy}

When a CMTR is available, the saturation RT impact energy of a specific cast SS is determined from chemical composition and ferrite content of the material. The ferrite content is calculated from chemical composition in terms of the Hull's equivalent factors 6 

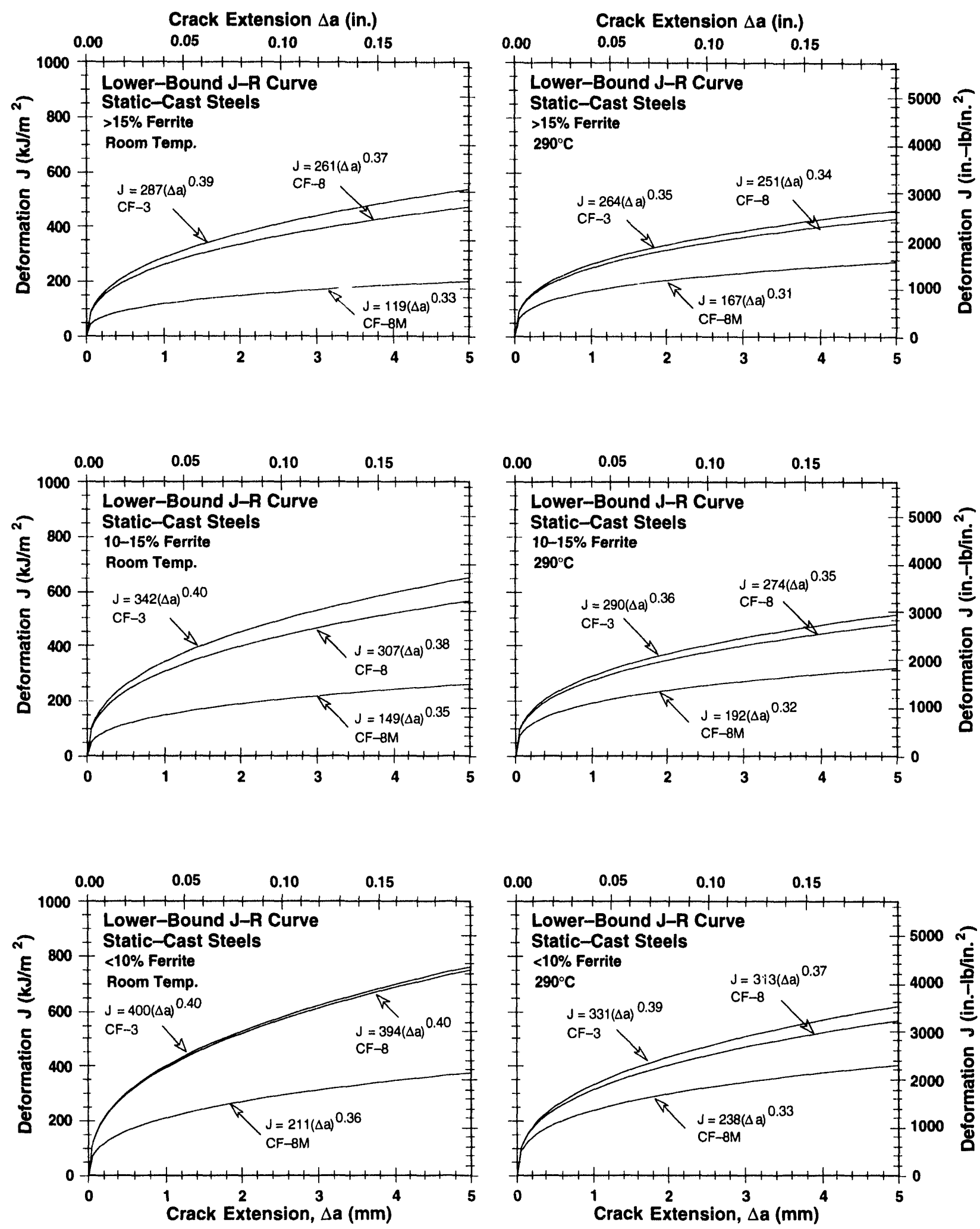

Figure 2. Lower-bound $J-R$ curves at $R T$ and $290^{\circ} \mathrm{C}$ for static-cast SSs with ferrite contents $>15,10-15$, or $<10 \%$ 

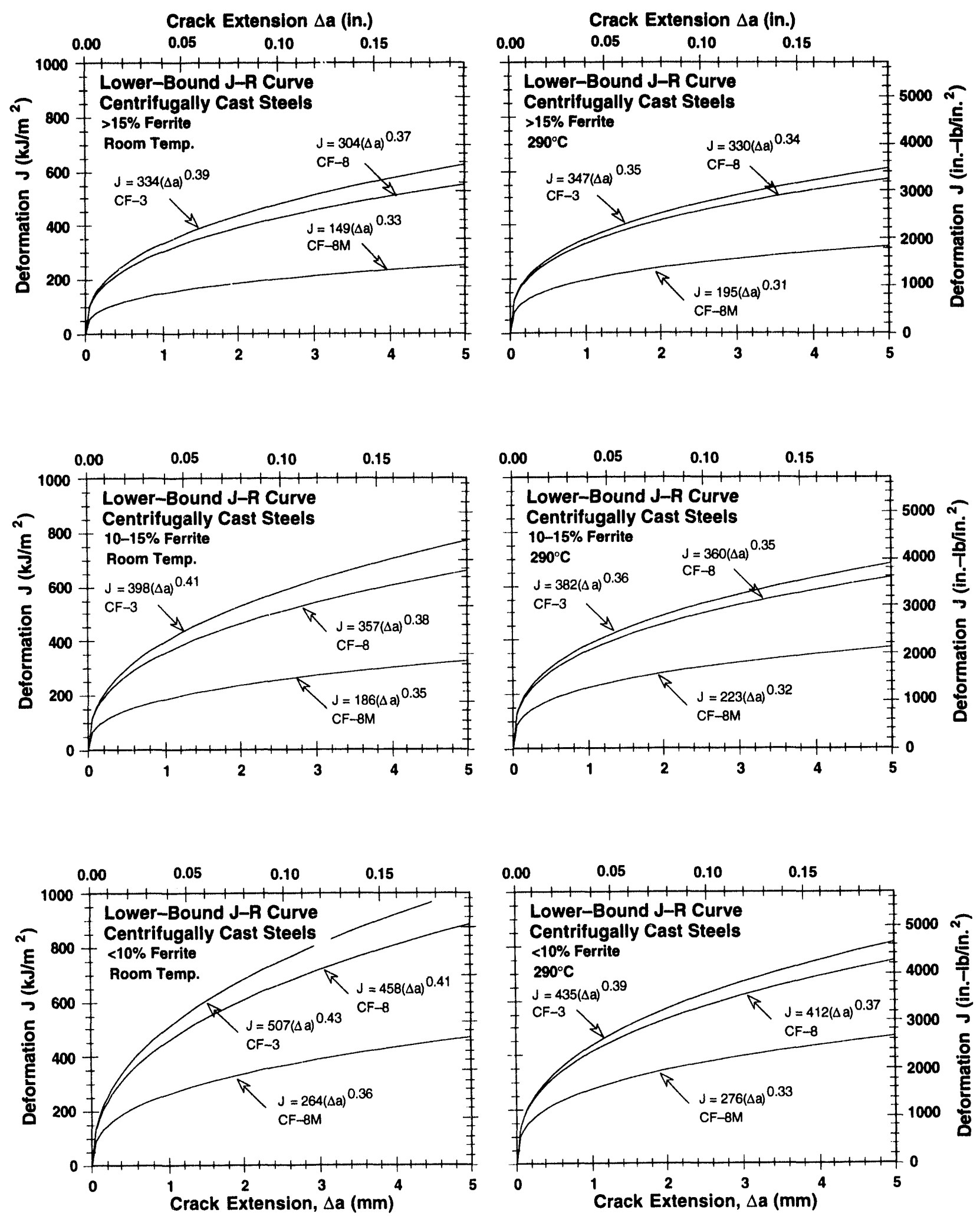

Figure 3. Lower-bound $J-R$ curves at $R T$ and $290^{\circ} \mathrm{C}$ for centrifugally cast SSs with ferrite contents $>15,10-15$, or $<10 \%$ 
Table 1. Values of coefficient $C$ ar. $\lambda$ exponent $n$ for lower-bound $J-R$ curve for cast SSs

\begin{tabular}{|c|c|c|c|c|c|c|c|c|}
\hline \multirow[b]{3}{*}{ Grade } & \multicolumn{4}{|c|}{ Static-Cast } & \multicolumn{4}{|c|}{ Centrifugally Cast } \\
\hline & \multicolumn{2}{|c|}{ Room Temp. } & \multicolumn{2}{|c|}{$290^{\circ} \mathrm{C}$} & \multicolumn{2}{|c|}{ Room Temp. } & \multicolumn{2}{|c|}{$290^{\circ} \mathrm{C}$} \\
\hline & $\mathrm{C}$ & $\mathrm{n}$ & $\mathrm{C}$ & $\mathbf{n}$ & $\mathrm{C}$ & $\mathbf{n}$ & $\mathrm{C}$ & $\mathbf{n}$ \\
\hline \multicolumn{9}{|c|}{ Ferrite Content $>15 \%$} \\
\hline CF-3 & 287 & 0.39 & 264 & 0.35 & 334 & 0.39 & 347 & 0.35 \\
\hline $\mathrm{CF}-8$ & 261 & 0.37 & 251 & 0.34 & 304 & 0.37 & 330 & 0.34 \\
\hline $\mathrm{CF}-8 \mathrm{M}^{\mathrm{a}}$ & 119 & 0.33 & 167 & 0.31 & 149 & 0.33 & 195 & 0.31 \\
\hline \multicolumn{9}{|c|}{ Ferrite Content $10-15 \%$} \\
\hline $\mathrm{CF}-3$ & 342 & 0.40 & 290 & 0.36 & 398 & 0.40 & 382 & 0.36 \\
\hline $\mathrm{CF}-8$ & 307 & 0.38 & 274 & 0.35 & 357 & 0.38 & 360 & 0.35 \\
\hline CF-8M & 149 & 0.35 & 192 & 0.32 & 186 & 0.35 & 223 & 0.32 \\
\hline \multicolumn{9}{|c|}{ Ferrite Content $<10 \%$} \\
\hline $\mathrm{CF}-3$ & 400 & 0.40 & 331 & 0.39 & 507 & 0.43 & 435 & 0.39 \\
\hline $\mathrm{CF}-8$ & 394 & 0.40 & 313 & 0.37 & 458 & 0.41 & 412 & 0.37 \\
\hline CF-8M & 211 & 0.36 & 238 & 0.33 & 264 & 0.36 & 276 & 0.33 \\
\hline
\end{tabular}

aThe lower-bound J-R curve for static-cast CF-8M steels may not be applicable for some compositions of steel that contain $\geq 25 \%$ ferrite and are very sensitive to thermal aging. See footnote page 2 .

$$
\mathrm{Cr}_{\text {eq }}=\mathrm{Cr}+1.21(\mathrm{Mo})+0.48(\mathrm{Si})-4.99
$$

and

$$
\mathrm{Ni}_{\mathrm{eq}}=(\mathrm{Ni})+0.11(\mathrm{Mn})-0.0086(\mathrm{Mn})^{2}+18.4(\mathrm{~N})+24.5(\mathrm{C})+2.77
$$

The concentration of $\mathrm{N}$ is often not available in the CMTR; if not known, it is assumed to be 0.04 wt. $\%$. The ferrite content $\delta_{\mathrm{c}}$ is given by

$$
\delta_{\mathrm{c}}=100.3\left(\mathrm{Cr}_{\mathrm{eq}} / \mathrm{Ni}_{\mathrm{eq}}\right)^{2}-170.72\left(\mathrm{Cr}_{\mathrm{eq}} / \mathrm{Ni}_{\mathrm{eq}}\right)+74.22
$$

Different correlations are used to estimate the saturation RT impact energy of the various grades of cast SS. To ensure that the estimates are either accurate or conservative for all heats, the saturation RT impact energy for a specific cast SS is determined by two different expressions, and the lower value is used for estimating fracture properties. For $\mathrm{CF}-3$ and $\mathrm{CF}-8$ steels, the saturation value of $\mathrm{RT}$ impact energy $\mathrm{C}_{\text {Vsat }}$ is the lower value determiaed from

$$
\log _{10} \mathrm{C}_{\text {Vsat }}=1.15+1.36 \exp (-0.035 \Phi)
$$

where the material parameter $\Phi$ is expressed as

$$
\Phi=\delta_{c}(C r+\mathrm{Si})(\mathrm{C}+0.4 \mathrm{~N})
$$

and from

$$
\begin{aligned}
\log _{10} \mathrm{CVsat}_{\mathrm{V}}= & 5.64-0.006 \delta_{\mathrm{c}}-0.185 \mathrm{Cr}+0.273 \mathrm{Mo}-0.204 \mathrm{Si} \\
& +0.044 \mathrm{Ni}-2.12(\mathrm{C}+0.4 \mathrm{~N}) .
\end{aligned}
$$


For $\mathrm{CF}-8 \mathrm{M}$ steel with $<10 \% \mathrm{Ni}$, the saturation value of $\mathrm{RT}$ impact energy $\mathrm{C}_{\mathrm{Vsa}}$ is the lower value determined from

$$
\log _{10} \mathrm{CVsat}_{\text {sat }}=1.10+2.12 \exp (-0.041 \Phi)
$$

where the material parameter $\Phi$ is expressed ${ }^{*}$ as

$$
\Phi=\delta_{\mathrm{C}}(\mathrm{Ni}+\mathrm{Si}+\mathrm{Mn})^{2}(\mathrm{C}+0.4 \mathrm{~N}) / 5
$$

and from

$$
\begin{aligned}
\log _{10} \mathrm{C}_{\text {Vsat }}= & 7.28-0.011 \delta_{c}-0.185 \mathrm{Cr}-0.369 \mathrm{Mo}-0.451 \mathrm{Si} \\
& -0.007 \mathrm{Ni}-4.71(\mathrm{C}+0.4 \mathrm{~N}) .
\end{aligned}
$$

For $\mathrm{CF}-8 \mathrm{M}$ steel with $>10 \% \mathrm{Ni}$, the saturation value of $\mathrm{RT}$ impact energy $\mathrm{C}_{\mathrm{Vsat}}$ is the lower value determined from

$$
\log _{10} \mathrm{C}_{\text {Vsat }}=1.10+2.64 \mathrm{exp}(-0.064 \Phi)
$$

where the material parameter $\Phi$ is expressed as

$$
\Phi=\delta_{c}(N i+S i+M n)^{2}(C+0.4 N) / 5
$$

and from

$$
\begin{aligned}
\log { }_{10} \mathrm{C}_{\text {Vsat }}= & 7.28-0.011 \delta_{\mathrm{c}}-0.185 \mathrm{Cr}-0.369 \mathrm{Mo}-0.451 \mathrm{Si} \\
& -0.007 \mathrm{Ni}-4.71(\mathrm{C}+0.4 \mathrm{~N}) .
\end{aligned}
$$

If not known, the $\mathrm{N}$ content in Eqs. 4-12 can be assumed to be 0.04 wt.\%. The ferrite content $\delta_{c}$ used in developing Eqs. 4-12 was calculated from Hull's equivalent factors. Using $\delta_{c}$ values determined by methods other than Hull's may result in nonconservative estimates of mechanical properties. For example, estimations of ferrite content based on ASTM A 800/A 800M 847 are $\approx 20 \%$ lower than those obtained from Hull's method for ferrite levels $>12 \%$ and are comparable for lower ferrite levels. Consequently, $\delta_{c}$ determined by the ASTM method for cast SSs with $>12 \%$ ferrite may yield nonconservative estimates of fracture properties.

The correlations expressed in Eqs. 4-12 have been validated with Charpy-impact and fracture toughness data from service-aged cast SS components from the decommissioned Shippingport reactor; the KRB reactor in Gundremmingen, Germany; and the Ringhals 2 reactor in Sweden. ${ }^{3}$ The correlations do not consider the effect of $\mathrm{Nb}$ and may not be applicable for $\mathrm{Nb}$-bearing steels. Also, they do not differentiate between product form, i.e., static-cast or centrifugally cast materials.

${ }^{*}$ For all compositions of CF-8M steel, material parameter $\Phi$ was expressed as $\delta_{C} \mathrm{Cr}(\mathrm{Ni}+\mathrm{Si})^{2}(\mathrm{C}+0.4 \mathrm{~N}) / 100$ in $\mathrm{Ref} .5$. 


\subsubsection{Fracture Toughness J-R Curve}

The saturation fracture toughness J-R curve for a specific cast SS can be estimated from its RT impact energy at saturation, $\mathrm{C}_{V \text { sat }}$. The saturation fracture toughness $\mathrm{J}-\mathrm{R}$ curve for static- and centrifugally cast steels is given by

$$
J_{d}=a\left(C_{v_{s a t}}\right)^{b}(\Delta a)^{n} \text {, }
$$

where the exponent $\mathrm{n}$ is given by

$$
\mathrm{n}=\mathrm{c}+\mathrm{d}\left(\log _{10} \mathrm{C}_{\mathrm{vsat}}\right)
$$

and the values of constants $a, b, c$, and $d$ for different grades of steel and test temperature are given in Tables 2 and 3 . The $\mathrm{J}-\mathrm{R}$ curve at any intermediate temperature can be linearly interpolated from the estimated values of $\mathrm{C}$ and $\mathrm{n}$ at $\mathrm{RT}$ and at $290^{\circ} \mathrm{C}$.

The correlations described in Eqs. 4-14 account for the degradation of mechanical properties of typical heats of cast SS. They do not consider the initial fracture properties of the unaged material. Some heats of cast SSs may have low initial fracture toughness, and estimates from Eqs. 4-14 may be higher than the initial value. Some knowledge regarding the initial fracture toughness of the material is therefore needed to justify the use of the estimated fracture toughness.

The CMTR for a specific cast SS component provides information on chemical composition, tensile strength, and possibly Charpy-impact energy of the material; fracture toughness is not available in CMTRs. At temperatures between $\mathrm{RT}$ and $320^{\circ} \mathrm{C}$, the minimum fracture toughness of unaged static-cast SSs can be expressed as

Table 2. Values of constants in Eq. 13 for estimating power-law $J-R$ curve

\begin{tabular}{|c|c|c|c|c|c|c|c|c|}
\hline \multirow[b]{3}{*}{ Grade } & \multicolumn{4}{|c|}{ Static-Cast } & \multicolumn{4}{|c|}{ Centrifugally Cast } \\
\hline & \multicolumn{2}{|c|}{ Room Temp. } & \multicolumn{2}{|c|}{$290^{\circ} \mathrm{C}$} & \multicolumn{2}{|c|}{ Room Temp. } & \multicolumn{2}{|c|}{$290^{\circ} \mathrm{C}$} \\
\hline & $\mathrm{a}$ & $\mathrm{b}$ & a & b & $\mathrm{a}$ & b & $\mathbf{a}$ & $\mathrm{b}$ \\
\hline$C F-3, C F-8$ & 49 & 0.52 & 102 & 0.28 & 57 & 0.52 & 134 & 0.28 \\
\hline $\mathrm{CF}-8 \mathrm{M}$ & 16 & 0.67 & 49 & 0.41 & 20 & 0.67 & 57 & 0.41 \\
\hline
\end{tabular}
for cast SSs

Table 3. Values of constants in Eq. 14 for estimating exponent $n$ of

\begin{tabular}{|c|c|c|c|c|}
\hline \multirow[b]{2}{*}{ Grade } & \multicolumn{2}{|c|}{ Room Temp. } & \multicolumn{2}{|c|}{$290^{\circ} \mathrm{C}$} \\
\hline & $\bar{c}$ & $\bar{d}$ & $\bar{c}$ & $\bar{d}$ \\
\hline $\mathrm{CF}-3$ & 0.15 & 0.16 & 0.17 & 0.12 \\
\hline $\mathrm{CF}-8$ & 0.20 & 0.12 & 0.21 & 0.09 \\
\hline $\mathrm{CF}-8 \mathrm{M}$ & 0.23 & 0.08 & 0.23 & 0.06 \\
\hline
\end{tabular}
power-law J-R curve for cast SSs 


$$
J_{d}=400(\Delta a)^{0.40} \text {, }
$$

and of centrifugally cast SSs as

$$
J_{d}=650(\Delta a)^{0.43} \text {. }
$$

When no information is available, these minimum fracture toughness $J-R$ curves may be used as the initial fracture toughness of a cast material. The fracture toughness $J-R$ curve for unaged material may also be obtained by using the initial RT Charpy-impact energy, CVint, instead of $\mathrm{C}_{V \text { sat }}$ in Eqs. 13 and 14. However, Eqs. 15 and 16 are used as a lower bound for the initial fracture toughness of the material. When the estimation based on CVint is lower than the minimum fracture toughness J-R curve expressed in Eqs. 15 and 16, the latter is used as the initial $\mathrm{J}-\mathrm{R}$ curve of the material.

When the initial fracture toughness or initial RT Charpy-impact energy for estimating fracture toughness of a material is known, and when the $\mathrm{J}-\mathrm{R}$ curve estimated from $\mathrm{C}_{\mathrm{Vsat}}$ and Eqs. 13 and 14 is higher than the initial fracture toughness of unaged material, the latter is used as the saturation J-R curve of the material. Such cases represent low-fracture-toughness materials that are relatively insensitive to thermal aging, i.e., fracture toughness of the material would not change during reactor service.

When no information is available on either the initial fracture toughness or initial RT Charpy-impact energy for estimating fracture toughness of a material, the minimum fracture toughness of unaged cast SSs is used as the upper bound for the predicted fracture toughness of the aged material. In other words, if the $\mathrm{J}-\mathrm{P}$ curve estimated from $\mathrm{C}_{\mathrm{V} \text { sat }}$ and Eqs. 13 and 14 is higher than the minimum fracture toughness of unaged cast SSs (i.e., Eqs. 15 and 16), the latter is used as the saturation $\mathrm{J}-\mathrm{R}$ curve of a material.

\subsection{Estimate for Steels of Known Composition and Service History: Service-Time Values}

The RT impact enurgy as a function of time and temperature of aging of a specific cast SS is determined from its estimated $\mathrm{RT}$ saturation impact energy $\mathrm{C}_{V \text { sat }}$ and the kinetics of embrittlement. The decrease in RT Charpy-impact energy $\mathrm{C}_{\mathrm{V}}$ with time is expressed as

$$
\left.\log _{10} C_{V}=\log _{10} C_{V s a t}+\beta \mid 1-\tanh [(P-\theta) / \alpha]\right\}
$$

where the aging parameter $\mathrm{P}$ is defined by

$$
P=\log _{10}(t)-\frac{1000 Q}{19.143}\left(\frac{1}{T_{S}+273}-\frac{1}{673}\right)
$$

The constants $\alpha$ and $\beta$ can be determined from $\mathrm{C}_{\text {Vint }}$ and $\mathrm{C}_{\mathrm{Vsat}}$ as follows:

$$
\alpha=-0.585+0.795 \log _{10} C_{V s a t}
$$

and 


$$
\beta=\left(\log _{10} \mathrm{C}_{\text {Vint }}-\log _{10} \mathrm{C}_{\mathrm{Vsat}}\right) / 2 .
$$

If $\mathrm{C}_{\mathrm{Vint}}$ is not known, a typical value of $200 \mathrm{~J} / \mathrm{cm}^{2}(118 \mathrm{ft} \cdot \mathrm{lb})$ may be used. The value of $\theta$ varies with service temperature; it is 3.3 for $<280^{\circ} \mathrm{C}\left(<536^{\circ} \mathrm{F}\right), 2.9$ for $280-330^{\circ} \mathrm{C}\left(536-626^{\circ} \mathrm{F}\right)$, and 2.5 for $330-360^{\circ} \mathrm{C}\left(626-680^{\circ} \mathrm{F}\right)$. Activation energy for thermal embrittlement is expressed in terms of both chemical composition and the constant $\theta$. The activation energy $Q$ is given by

$$
\begin{aligned}
\mathrm{Q}= & 10\left[74.52-7.20 \theta-3.46 \mathrm{Si}-1.78 \mathrm{Cr}-4.35 \mathrm{I}_{1} \mathrm{Mn}\right. \\
& \left.+\left(148-125 \mathrm{I}_{1}\right) \mathrm{N}-61 \mathrm{I}_{2} \mathrm{C}\right]
\end{aligned}
$$

where the indicators $I_{1}=0$ and $I_{2}=1$ for CF-3 or CF-8 steels and assume the values of 1 and 0 , respectively, for CF-8M steels. Equation 21 is based on Charpy-impact data obtained from materials that were aged up to $58,000 \mathrm{~h}$ at $290-400^{\circ} \mathrm{C}\left(554-752^{\circ} \mathrm{F}\right)$ and is an updated version ${ }^{*}$ of an expression presented earlier. ${ }^{5}$ It is applicable to compositions within ASTM Specification A 351, with an upper limit of $1.2 \mathrm{wt} . \%$ for Mn content. Actual Mn content is used when materals contain up to $1.2 \mathrm{wt} . \% \mathrm{Mn}$; for steels containing $>1.2 \mathrm{wt} . \% \mathrm{Mn}, 1.2 \mathrm{wt} . \%$ is assumed. Furthermore, the values of $\mathrm{Q}$ predicted from Eq. 21 should be between $65 \mathrm{~kJ} / \mathrm{mole}$ (15.5 kcal/mole) minimum and $250 \mathrm{~kJ} / \mathrm{mole}(59.8 \mathrm{kcal} / \mathrm{mole})$ maximum; $Q$ is assumed to be $65 \mathrm{~kJ} / \mathrm{mole}$ if the predicted values are lower, and $250 \mathrm{~kJ} /$ mole if the predicted values are higher.

The RT Charpy-impact energy of a specific cast SS as a function of service time and temperature can be obtained from estimated $\mathrm{C}_{V s a t}$ (Eqs. 4-12) and the kinetics of embrittlement (Eqs. 17-21). The fracture toughness J-R curve is then obtained by using the estimated RT Charpy-impact energy $C_{V}$ in Eqs. 13 and 14. However, depending on the available information, minimum fracture toughness of cast SSs (Eqs. 15 or 16) or initial fracture toughness of the unaged material is used as the upper bound for the estimations.

\section{Conclusions}

A procedure and correlations are presented for predicting Charpy-impact energy and fracture toughness J-R curve of aged cast SSs (ASTM A 351) from known material information. Mechanical properties of a specific cast SS are estimated from the extent and kinetics of thermal embrittlement. Embrittlement of cast SSs is characterized in terms of RT Charpy-impact energy. The extent or degree of thermal embrittlement at "saturation," i.e., the minimum impact energy that can be achieved for the material after long-term aging, is determined from chemical composition of the steel. Charpy-impact energy as a function of time and temperature of reactor service is estimated from the kinetics of thermal embrittlement, which is also determined from the chemical composition. The initial impact energy of the unaged steel is required for these estimations. The fracture toughness $J-R$ curve for the material is then obtained from correlations between RT Charpy-impact energy and fracture toughness parameters. A common "predicted lower-bound" J-R curve for cast SSs with unknown chemical composition is also defined for a given grade of steel, range of ferrite contents, and temperature. Typical examples for estimating fracture properties of cast SS components during reactor service are described in the Appendix.

\footnotetext{
"The updated expression for $\mathrm{CF}-8 \mathrm{M}$ steel is essentially an optimized version of the earlier expression. For $\mathrm{CF}-3$ and $\mathrm{CF}-8$ steels, the effect of Mo and Mn content has been omitted and the effect of $\mathrm{C}$ has been added in the updated expression.
} 


\section{References}

1. O. K. Chopra, "Thermal Aging of Cast Stainless Steels in LWR Systems: Estimation of Mechanical Properties," in Nuclear Plant Systems/Components Aging Management and Life Extension, I. T. Kisisel, J. Sinnappan, R. W.. Carlson, and W. H. Lake, eds., PVP Vol. 228, ASME, New York, pp. 79-92 (1992).

2. O. K. Chopra, "Prediction of Aging Degradation of Cast Stainless Steel Components in LWR Systems," in Proceedings of the Aging Research Information Conference, NUREG/CP-0122, Vol. 2, pp. 324-340 (1992).

3. O. K. Chopra, "Evaluation of Aging Degradation of Structural Components," in Proceedings of the Aging Research Information Conference, NUREG/CP-0122, Vol. 2, pp. 369-386 (1992).

4. C. Jansson, "Degradation of Cast Stainless Steel Elbows after 15 Years in Service," presented at Fontevraud II Intl. Symp., Sept. 10-14, 1990, Royal Abbey of Fontevraud, France.

5. O. K. Chopra, Estimation of Fracture Toughness of Cast Stainless Steels during Thermal Aging in LWR Systems, NUREG/CR-4513, ANL-90/42 (June 1991).

6. L. S. Aubrey, P. F. Wieser, W. J. Pollard, and E. A. Schoefer, "Ferrite Measurement and Control in Cast Duplex Stainless Steel," in SS Castings, V. G. Behal and A. S. Melilli, eds., STP 756, ASTM, Philadelphia, PA, pp. 126-164 (1982).

7. Standard Practice for Steel Casting, Austenitic Alloy, Estimating Ferrite Content Thereof, ASTM Designation A 800/A 800M-84, American Society for Testing and Materials, Philadelphia, PA (1984). 


\section{Appendix}

\section{Estimation of Fracture Properties of Cast SSs}

The correlations described in this report can be used for assessing thermal embrittlement of cast SS components. The procedure involves a few simple steps. First, avallable information about the material and service condition is obtained from the CMTR; i.e., if known, determine the chemical composition, grade of steel, casting method, Charpy-impact properties, and time and temperature of service. Then, on the basis of available information, various schemes are used to estimate the fracture toughness J-R curve and Charpy-impact energy of the aged material. Typical examples for estimating fracture properties of cast SS components during reactor service are presented.

Example 1. A centrifugally cast $\mathrm{CF}-8$ pipe, $0.51 \mathrm{~m}$ nominal diameter, in service at $302^{\circ} \mathrm{C}$ $\left(575^{\circ} \mathrm{F}\right)$ for 18 effective full power years (efpys). The following material information is also known.

\section{Measured Ferrite Content (\%): 14.2}

Only the lower-bound fracture toughness $J-R$ curve can be estimated for this steel, because only the grade and ferrite content are known" and the chemical composition of the material is not known. The estimation scheme for this example involves one step and is shown in Fig. A-1. The lower-bound fracture toughness represents the minimum toughness that can be achieved after long-term aging by centrifugally cast CF-8 steels containing $10-15 \%$ ferrite.

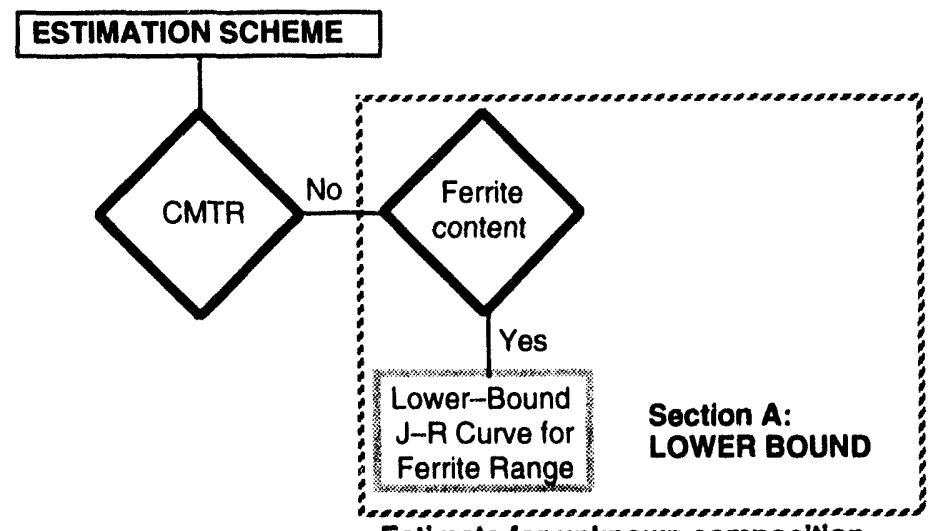

Estimate for unknown composition

Figure A-1. Estimation scheme for Example 1

Step 1. From Table 1 the predicted lower-bound fracture toughness J-R curve for centrifugally cast $\mathrm{CF}-8$ steel with $10-15 \%$ ferrite, at RT, is given by

$$
\mathrm{J}_{\mathrm{d}}\left(\mathrm{kJ} / \mathrm{m}^{2}\right)=357[\Delta \mathrm{a}(\mathrm{mm})]^{0.38}
$$

\footnotetext{
* $\mathrm{CF}-8 \mathrm{M}$ steel and $>15 \%$ ferrite are assumed if the grade and ferrite content of the steel are not known.
} 
and at $290^{\circ} \mathrm{C}\left(554^{\circ} \mathrm{F}\right)$ by

$$
\mathrm{J}_{\mathrm{d}}\left(\mathrm{kJ} / \mathrm{m}^{2}\right)=360[\Delta \mathrm{a}(\mathrm{mm})]^{0.35}
$$

The $\mathrm{J}-\mathrm{R}$ curve at a service temperature of $302^{\circ} \mathrm{C}$ can be linearly extrapolated from Eqs. A-1.1 and $\mathrm{A}-1.2$. The curve at $302^{\circ} \mathrm{C}$ is not significantly different from that at $290^{\circ} \mathrm{C}$ and can be approximated as

$$
\mathrm{J}_{\mathrm{d}}\left(\mathrm{kJ} / \mathrm{m}^{2}\right)=360|\Delta \mathrm{a}(\mathrm{mm})|^{0.35}
$$

Example 2. A static-cast $\mathrm{CF}-8$ check valve in service at $282^{\circ} \mathrm{C}\left(540^{\circ} \mathrm{F}\right)$. The following material information is also known.

Chem. Comp. (wt.\%): Cr, 20.26; Mo, 0.01; Si, 1.45; Ni, 8.84; Mn. 1.10; C, 0.056; N, 0.041

Measured Ferrite Content (\%): 10.4

RT Charpy-Impact Energy (J): 150.4

Only the saturation fracture properties can be estimated in this case, because the time of service is not known. The estimation scheme for this example is shown in Fig. A-2. The saturation fracture toughness represents the minimum toughness that can be achieved by this specific cast SS after long-term aging.

Step 1. The calculated ferrite content (Eqs. 1-3) is

$$
\delta_{c}(\%)=10.8 \text {. }
$$

Step 2. The material parameter $\Phi$ for $\mathrm{CF}-8$ steel (Eq. 5) is 16.94. Saturation RT Charpy-impact energy in terms of $\Phi$ (Eq. 4) is $79.8 \mathrm{~J} / \mathrm{cm}^{2}$, and in terms of composition (Eq. 6), it is $58.8 \mathrm{~J} / \mathrm{cm}^{2}$. The lower of the two values is used for fracture toughness estimations; thus

$$
C_{V s a t}\left(\mathrm{~J} / \mathrm{cm}^{2}\right)=58.8 \text {. }
$$

Step 3. The saturation fracture toughness J-R curve for static-cast CF-8 steel, at RT (Eqs. 13, 14 and Tables 2 and 3), is given by

$$
\mathrm{J}_{\mathrm{d}}\left(\mathrm{kJ} / \mathrm{m}^{2}\right)=407.8[\Delta \mathrm{a}(\mathrm{mm})]^{0.41}
$$

and at $290^{\circ} \mathrm{C}$, by

$$
\left.\mathrm{J}_{\mathrm{d}}\left(\mathrm{kJ} / \mathrm{m}^{2}\right)=319.2 \mid \Delta \mathrm{a}(\mathrm{mm})\right]^{0.37} \text {. }
$$

The saturation fracture toughness $\mathrm{J}-\mathrm{R}$ curve at a service temperature of $282^{\circ} \mathrm{C}$ is linearly interpolated from Eqs. A-2.1 and A-2.2. The curve at $282^{\circ} \mathrm{C}$ is not significantly different from that at $290^{\circ} \mathrm{C}$ and can be approximated as

$$
\mathrm{J}_{\mathrm{d}}\left(\mathrm{kJ} / \mathrm{m}^{2}\right)=319.2[\Delta \mathrm{a}(\mathrm{mm})]^{0.37} \text {. }
$$




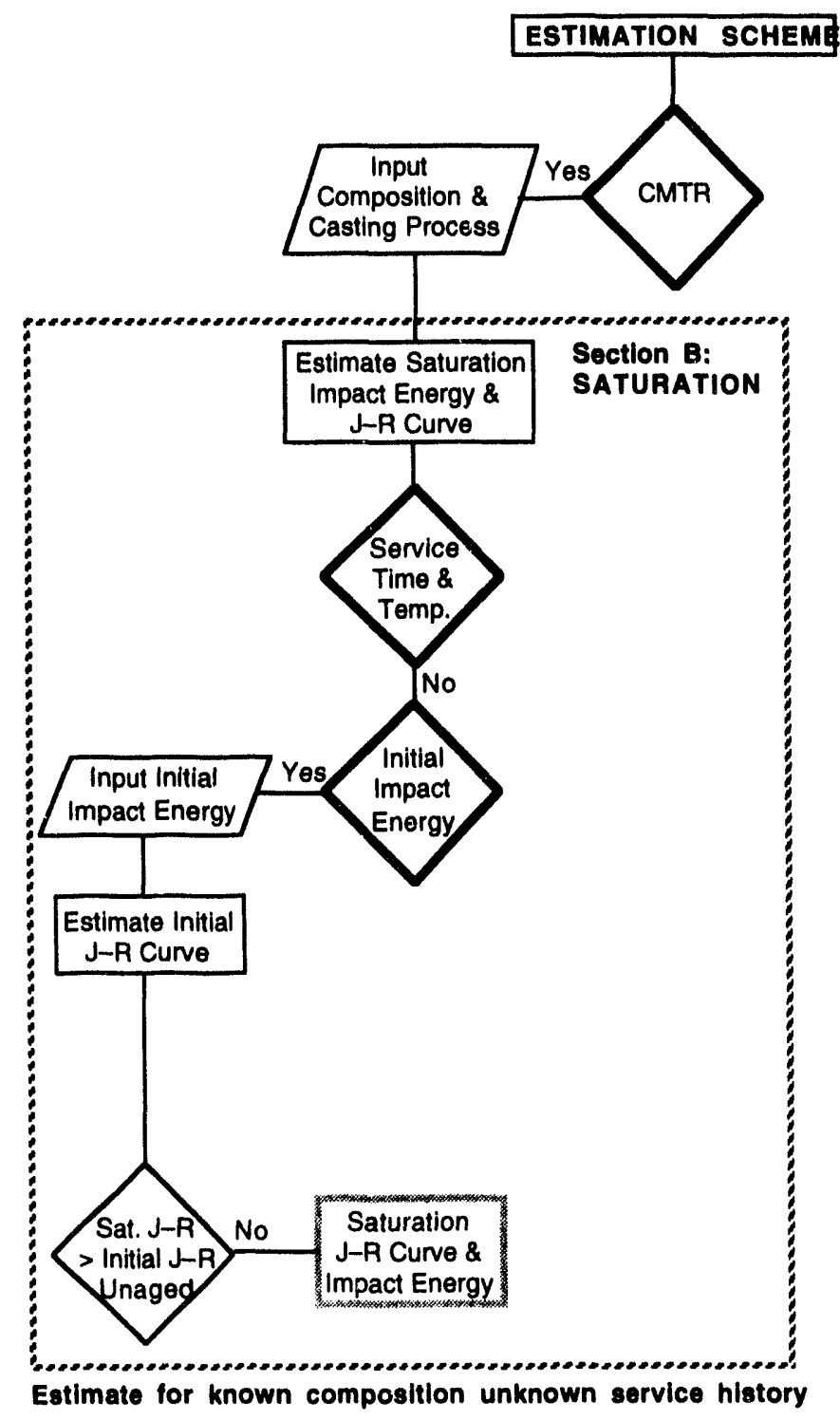

Figure A-2. Estimation scheme for Example 2

This corresponds to a $J_{d}$ value of $579 \mathrm{~kJ} / \mathrm{m}^{2}\left(3306 \mathrm{in} . \cdot \mathrm{lb} / \mathrm{in} .{ }^{2}\right)$ at $5-\mathrm{mm}$ crack extension.

Step 4. The initial RT Charpy-impact energy is $150.4 \mathrm{~J}$. The normalized value is obtained by dividing this value by the cross-sectional area of the Charpy-impact specimen, $1 . e ., 0.8 \mathrm{~cm}^{2}$.

$$
C_{V i n t}\left(J / \mathrm{cm}^{2}\right)=188.0 \text {. }
$$

Step 5. The initial J-R curve for the unaged material is the higher of either Eq. 15 or the $J-R$ curve determined from Eqs. 13 and 14 using $C_{V i n t}$ instead of $C_{V s a t}$. The initial $J-R$ curve at $282^{\circ} \mathrm{C}$ is not significantly different from that at $290^{\circ} \mathrm{C}$ and can be approximated as

$$
\mathrm{J}_{\mathrm{d}}\left(\mathrm{kJ} / \mathrm{m}^{2}\right)=441.9[\Delta \mathrm{a}(\mathrm{mm})]^{0.41} \text {. }
$$

\footnotetext{
"In this report, all values of impact energy are considered to be for a standard Charpy-V-notch specimen (ASTM Specification E 23), 1.e., $10 \times 10-\mathrm{mm}$ cross section and 2-mm V notch.
} 
This corresponds to a $\mathrm{J}_{\mathrm{d}}$ value of $855 \mathrm{~kJ} / \mathrm{m}^{2}\left(4881 \mathrm{in.} \cdot \mathrm{lb} / \mathrm{in} .{ }^{2}\right)$ at $5-\mathrm{mm}$ crack extension. Thermal aging decreases the fracture toughness of this steel from 855 to $579 \mathrm{~kJ} / \mathrm{m}^{2}$ in the fully aged condition.

Example 3. A centrifugally cast CF-8M pipe, $0.51 \mathrm{~m}$ nominal diameter, in service at $291{ }^{\circ} \mathrm{C}$ $\left(555^{\circ} \mathrm{F}\right)$. The following material information is also known.

Chem. Comp. (wt.\%): Cr, 20.64; Mo, 2.05; Si, 1.02; Ni, 10.00; Mn, 1.07; C, 0.040; N, 0.151

Charpy-Impact Energy (J): $\quad 181.6$

This example is similar to the previous example and only the saturation fracture properties can be estimated because the time of service is not known. The estimation scheme for this example is shown in Fig. A-3. The saturation fracture toughness represents the minimum toughness that can be achieved by this specific cast SS after long-term aging.

Step 1. The calculated ferrite content (Eqs. 1-3) is

$$
\delta_{c}(\%)=8.8
$$

Step 2. The material parameter $\Phi$ for static-cast CF-8M steel with $>10 \%$ Ni (Eq. 11) is 25.80 . Saturation RT Charpy-impact energy in terms of $\Phi$ (Eq. 10) is $40.4 \mathrm{~J} / \mathrm{cm}^{2}$, and in terms of composition (Eq. 12), it is $40.3 \mathrm{~J} / \mathrm{cm}^{2}$. The lower of the two values is used for fracture toughness estimations; thus

$$
C_{\text {Vsat }}\left(\mathrm{J} / \mathrm{cm}^{2}\right)=40.3 \text {. }
$$

Step 3. The saturation fracture toughness $\mathrm{J}-\mathrm{R}$ curve for static-cast CF-8M steel, at a service temperature of $291^{\circ} \mathrm{C}$ (Eqs. 13, 14 and Tables 2 and 3), can be approximated as

$$
\mathrm{J}_{\mathrm{d}}\left(\mathrm{kJ} / \mathrm{m}^{2}\right)=259.5[\Delta \mathrm{a}(\mathrm{mm})]^{0.33} \text {. }
$$

This corresponds to a $J_{d}$ value of $441 \mathrm{~kJ} / \mathrm{m}^{2}\left(2520 \mathrm{ln} .1 \mathrm{~b} / \mathrm{in} .{ }^{2}\right)$ at 5-mm crack extension.

Step 4. The initial RT Charpy-impact energy is $181.6 \mathrm{~J}$. The normalized value is obtained by dividing this value by $0.8 \mathrm{~cm}^{2}$, the cross-sectional area of the Charpy-impact specimen.

$$
C_{\text {Vint }}\left(\mathrm{J} / \mathrm{cm}^{2}\right)=227.0 \text {. }
$$

Step 5. The initial J-R curve for the unaged material is the higher of either Eq. 16 or the $J-R$ curve determined from Eqs. 13 and 14 using $\mathrm{C}_{\text {Vini }}$ instead of $\mathrm{C}_{V \text { sat }}$. The initial J-R curve, at $291^{\circ} \mathrm{C}$ is essentially the same as that at $290^{\circ} \mathrm{C}$

$$
\mathrm{J}_{\mathrm{d}}\left(\mathrm{kJ} / \mathrm{m}^{2}\right)=527.0[\Delta \mathrm{a}(\mathrm{mm})]^{0.37} \text {. }
$$

This corresponds to a $J_{d}$ value of $956 \mathrm{~kJ} / \mathrm{m}^{2}\left(5459 \mathrm{in} . \cdot \mathrm{lb} / \mathrm{in} .{ }^{2}\right)$ at $5-\mathrm{mm}$ crack extension. Thermal aging decreases the fracture toughness of this steel from 956 to $441 \mathrm{~kJ} / \mathrm{m}^{2}$ in the fully aged condition. 


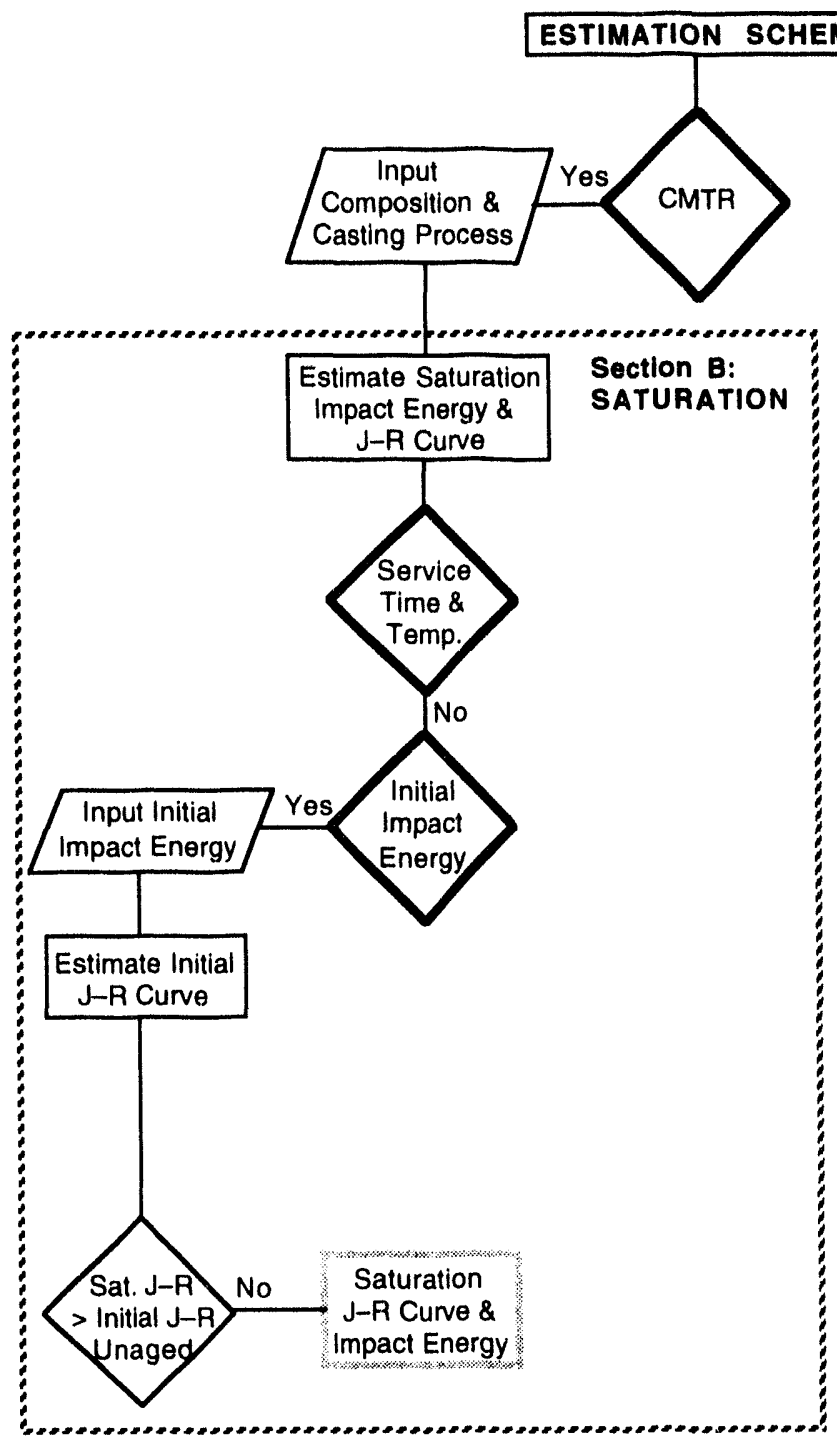

Estimate for known composition unknown service history

Figure A-3. Estimation scheme for Example 3

Example 4. A static-cast CF-8M elbow, $0.66 \mathrm{~m}$ nominal size, in service at $325^{\circ} \mathrm{C}\left(617^{\circ} \mathrm{F}\right)$ for 9 efpys. The following material information is also known.

Chem. Comp. (wt.\%): Cr, 20.21; Mo, 2.09; Si, 1.03; Ni. 10.24; Mn, 0.77; C, 0.037; N, 0.044

Charpy-Impact Energy (J): 209.6

Service time, as well as saturation fracture properties, can be estimated in this case, because both chemical composition and service conditions for the material are known. The estimation scheme for this example is shown in Fig. A-4. The saturation fracture toughness represents the minimum toughness that can be achieved by this cast SS after long-term aging and the service time fracture toughness is the value after 9 efpys of service at $325^{\circ} \mathrm{C}$.

Step 1. The calculated ferrite content (Eqs. 1-3) is

$$
\delta_{\mathrm{c}}(\%)=16.1 \text {. }
$$


Step 2. The material parameter $\Phi$ for static-cast CF-8M steel with $>10 \%$ Ni (Eq. 11) is 25.56 . Saturation RT Charpy-impact energy in terms of $\Phi$ (Eq. 10) is $41.1 \mathrm{~J} / \mathrm{cm}^{2}$, and in terms of composition (Eq. 12), it is $62.9 \mathrm{~J} / \mathrm{cm}^{2}$. The lower of the two values is used for fracture toughness estimations; thus

$$
C_{\text {Vsat }}\left(\mathrm{J} / \mathrm{cm}^{2}\right)=41.1 \text {. }
$$

Step 3. The saturation fracture toughness J-R curve for this static-cast CF-8M steel, at RT (Eqs. 13, 14 and Tables 2 and 3), is given by

$$
\mathrm{J}_{\mathrm{d}}\left(\mathrm{kJ} / \mathrm{m}^{2}\right)=193[\Delta \mathrm{a}(\mathrm{mm})]^{0.36}
$$

and at $290^{\circ} \mathrm{C}$, by

$$
\mathrm{J}_{\mathrm{d}}\left(\mathrm{kJ} / \mathrm{m}^{2}\right)=225[\Delta \mathrm{a}(\mathrm{mm})]^{0.33} \text {. }
$$

The saturation-fracture-toughness $\mathrm{J}-\mathrm{R}$ curve at a service temperature of $325^{\circ} \mathrm{C}$ is linearly extrapolated from Eqs. A-4.1 and A-4.2 as

$$
\left.\mathrm{J}_{\mathrm{d}}\left(\mathrm{kJ} / \mathrm{m}^{2}\right)=229 \mid \Delta \mathrm{a}(\mathrm{mm})\right]^{0.33} \text {. }
$$

This corresponds to a $J_{d}$ value of $389 \mathrm{~kJ} / \mathrm{m}^{2}\left(2224 \mathrm{in.} \cdot \mathrm{lb} / \mathrm{in} .{ }^{2}\right)$ at $5-\mathrm{mm}$ crack extension.

Step 4. The kinetics for thermal embrittlement of this steel, i.e., the activation energy $\mathrm{Q}$, and aging parameter $\mathrm{P}$ corresponding to 9 efpys $(78840 \mathrm{~h})$ of service at $325^{\circ} \mathrm{C}\left(617^{\circ} \mathrm{F}\right)$ are estimated from chemical composition and service conditions.

$$
\begin{array}{ll}
\theta=2.9 & \text { for service temperatures of } 280-320^{\circ} \mathrm{C} . \\
Q(\mathrm{~kJ} / \mathrm{mole})=117.6 & \text { from Eq. } 21\left(\text { with } \mathrm{I}_{1}=1 \text { and } \mathrm{I}_{2}=0\right) . \\
\mathrm{P}=3.752 & \text { from Eq. } 18 .
\end{array}
$$

Step 5. The initial RT Charpy-impact energy is $209.6 \mathrm{~J}$. The normalized value is obtained by dividing by the cross-sectional area of the Charpy-impact specimen, i.e., $0.8 \mathrm{~cm}^{2}$.

$$
\mathrm{C}_{\text {Vint }}\left(\mathrm{J} / \mathrm{cm}^{2}\right)=262.0 \text {. }
$$

Step 6. The initial $\mathrm{J}-\mathrm{R}$ curve for the unaged material is the higher of either Eq. 15 or the $\mathrm{J}-\mathrm{R}$ curve determined from Eqs. 13 and 14 using $C_{V i n t}$ instead of $C_{V s a t}$. In this example, the initial $\mathrm{J}-\mathrm{R}$ curve at RT is obtained from Eqs. 13 and 14 as

$$
\left.\mathrm{J}_{\mathrm{d}}\left(\mathrm{kJ} / \mathrm{m}^{2}\right)=667 \mid \Delta \mathrm{a}(\mathrm{mm})\right]^{0.42}
$$

and at $290^{\circ} \mathrm{C}$ as

$$
J_{\mathrm{d}}\left(\mathrm{kJ} / \mathrm{m}^{2}\right)=481|\Delta \mathrm{a}(\mathrm{mm})|^{0.38} .
$$




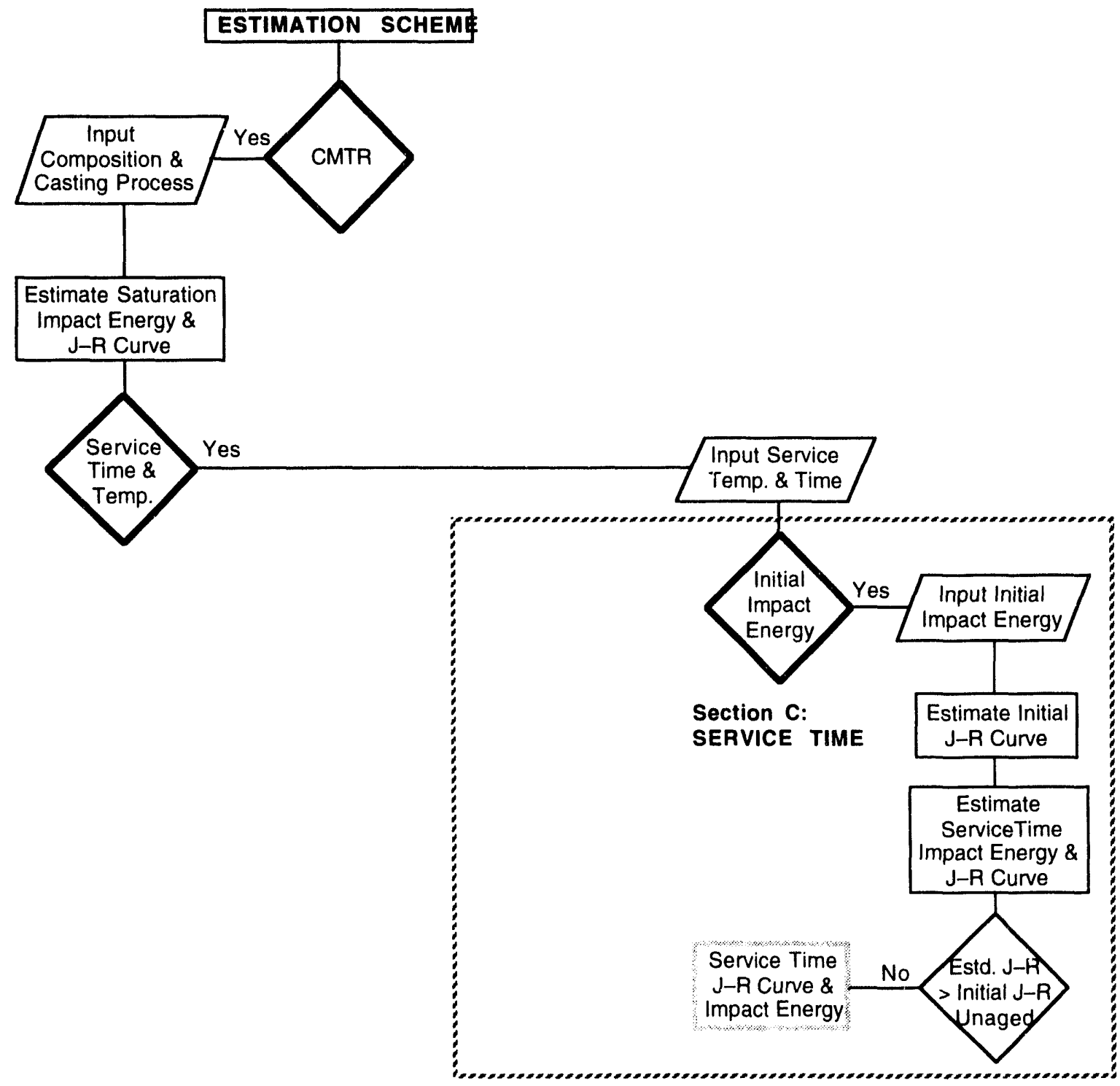

Figure A-4. Estimation scheme for Example 4

The initial-fracture-toughness $\mathrm{J}-\mathrm{R}$ curve at a service temperature of $325^{\circ} \mathrm{C}$ is linearly extrapolated from Eqs. A-4.4 and A-4.5 as

$$
\mathrm{J}_{\mathrm{d}}\left(\mathrm{kJ} / \mathrm{m}^{2}\right)=456\left[\left.\Delta \mathrm{a}(\mathrm{mm})\right|^{0.37}\right. \text {. }
$$

This corresponds to a $J_{d}$ value of $827 \mathrm{~kJ} / \mathrm{m}^{2}\left(4723 \mathrm{in} . \cdot \mathrm{lb} / \mathrm{in} .{ }^{2}\right)$ at 5-mm crack extension.

Step 7. The constants in Eq. 17 are obtained from $\mathrm{C}_{V \text { sat }}$ and $\mathrm{C}_{\text {Vint }}$.

$$
\begin{array}{lr}
\alpha=0.698 & \text { from Eq. } 19 . \\
\beta=0.402 & \text { from Eq. 20. }
\end{array}
$$


Step 8. Information from steps 2 and 7 are used to determine the Charpy-impact energy $\mathrm{C}_{V}$ after 9 efpys at $325^{\circ} \mathrm{C}$.

$$
\mathrm{C}_{\mathrm{v}}\left(\mathrm{J} / \mathrm{cm}^{2}\right)=47.7 \quad \text { from Eq. } 17 .
$$

Step 9. The service-time-fracture-toughness $\mathrm{J}-\mathrm{R}$ curve for static-cast $\mathrm{CF}-8 \mathrm{M}$ steel, at RT, is given by

$$
\mathrm{J}_{\mathrm{d}}\left(\mathrm{kJ} / \mathrm{m}^{2}\right)=213[\Delta \mathrm{a}(\mathrm{mm})]^{0.36}
$$

and at $290^{\circ} \mathrm{C}$, by

$$
\mathrm{J}_{\mathrm{d}}\left(\mathrm{kJ} / \mathrm{m}^{2}\right)=239[\Delta \mathrm{a}(\mathrm{mm})]^{0.33}
$$

The service-time-fracture-toughness $\mathrm{J}-\mathrm{R}$ curve at a service temperature of $325^{\circ} \mathrm{C}$ is linearly extrapolated from Eqs. A-4.7 and A-4.8 as

$$
\mathrm{J}_{\mathrm{d}}\left(\mathrm{kJ} / \mathrm{m}^{2}\right)=242[\Delta \mathrm{a}(\mathrm{mm})]^{0.33} \text {. }
$$

This corresponds to a $J_{d}$ value of $412 \mathrm{~kJ} / \mathrm{m}^{2}\left(2350 \mathrm{in} . \cdot \mathrm{lb} / \mathrm{in} .{ }^{2}\right)$ at 5-mm crack extension.

Thermal aging decreases the fracture toughness of this steel from 827 to $412 \mathrm{~kJ} / \mathrm{m}^{2}$ after 9 efpy of service at $325^{\circ} \mathrm{C}$; the saturation fracture toughness in the fully aged condition corresponds to a $\mathrm{J}_{\mathrm{d}}$ value of $389 \mathrm{~kJ} / \mathrm{m}^{2}$. 


\section{Distribution for NUREG/CR-6177 (ANL-94/2)}

Internal:

O. K. Chopra (20)

H. M. Chung

T. F. Kassner

C. Malefyt
R. B. Poeppel

W. J. Shack (5)

C. E. Till

R. W. Weeks

TIS Files

\section{External:}

NRC, for distribution per R5

ANL Libraries

ANL $-\mathrm{E}$

ANL $-W$

Manager, Chicago Field Office, DOE

Energy Technology Division Review Committee

H. K. Birnbaum, University of Illinois, Urbana, IL

R. C. Buchanan, University of Cincinnati, Cincinnati, $\mathrm{OH}$

M. S. Dresselhaus, Massachusetts Institute of Technology, Cambridge, MA

B. G. Jones, University of Illinois, Urbana, IL

C.-Y. Li, Cornell University, Ithaca, NY

S.-N. Liu, Fremont, CA

R. E. Smith, SciTech, Inc., Morrisville, NC

D. Atteridge, Battelle Pacific Northwest Laboratory, Richland

W. H. Bamford, Westinghouse Electric Corp., Pittsburgh, PA

K. K. Bandyopadhyay, Brookhaven National Laboratory, Upton, NY.

J. A. Christensen, Pacific Northwest Laboratories, Richland

N. G. Cofie, Nutech, San Jose, CA

A. Cowan, Risley Nuclear Power Development Labs., Risley, Warrington, UK

E. L. Creamer, Shell Oil Co., Houston, TX

W. H. Cullen, Materials Engineering Associates, Inc., Lanham, MD

B. J. L. Darlaston, Berkeley Nuclear Laboratories, Berkeley, Gloucestershire, UK

H. Domian, Alliance Research Center, Babcock \& Wilcox Co., Alliance, OH

G. Gage, AEA Technology, Harwell Laboratory, Oxfordshire, UK

J. Gilman, Electric Power Research Inst., Palo Alto, CA

W. Gysel, Georg Fischer, Ltd., Schaffhausen, Switzerland

G. E. Hale, The Welding Institute, Abington, Cambridge, UK

P. Hedgecock, APTECH Engineering Services, Inc., Paln Alto, CA

B. Hemsworth, HM Nuclear Installations Inspectorate, London

J. Jansky, Buro für Technische Beratung, Leonberg, Germany

C. E. Jaske, CC Technologies, Cortest, Columbus, OH

C. Kim. Westinghouse Electric Corp., Pittsburgh

P. M. Lang, Office of Converter Reactor Deployment, U.S. Dept. of Energy, Washington, DC

G. J. Licina, Structural Integrity Associates, San Jose, CA

T. R. Mager, Westinghouse Electric Corp., Pittsburgh

Y. Meyzaud, Framatome, Paris La Defense, France

M. Prager, Materials Properties Council, Inc., New York 
P. H. Pumphrey, National Power, Technology and Environment Center, Leatherhead, Surrey, UK

D. Quiñones, Robert Cloud \& Associates, Berkeley, CA

C. Y. Rieg, Electricité de France, Villeurbanne Cedex, France

V. N. Shah, EG\&G Idaho, Inc., Idaho Falls, Idaho

V. K. Sikka, Oak Ridge National Laboratory

A. Singh, Unical Science \& Technology Division, Brea, CA

G. Slama, Framatome, Paris La Defense, France

G. D. W. Smith, Oxford University, Oxford, UK

H. D. Solomon, General Electric Co., Schenectady, NY

D. M. Stevens, Lynchburg Research Center, Babcock \& Wilcox Co., Lynchburg, VA

L. Taylor, Nuclear Electric plc., Chelsford Rd., Knutsford, Cheshire, UK

J. C. Van Duysen, Electricité de France, Moret-Sur-Loing, France

J. M. Vitek, Oak Ridge National Laboratory

J. Wilks, AMOCO, Naperville, IL 

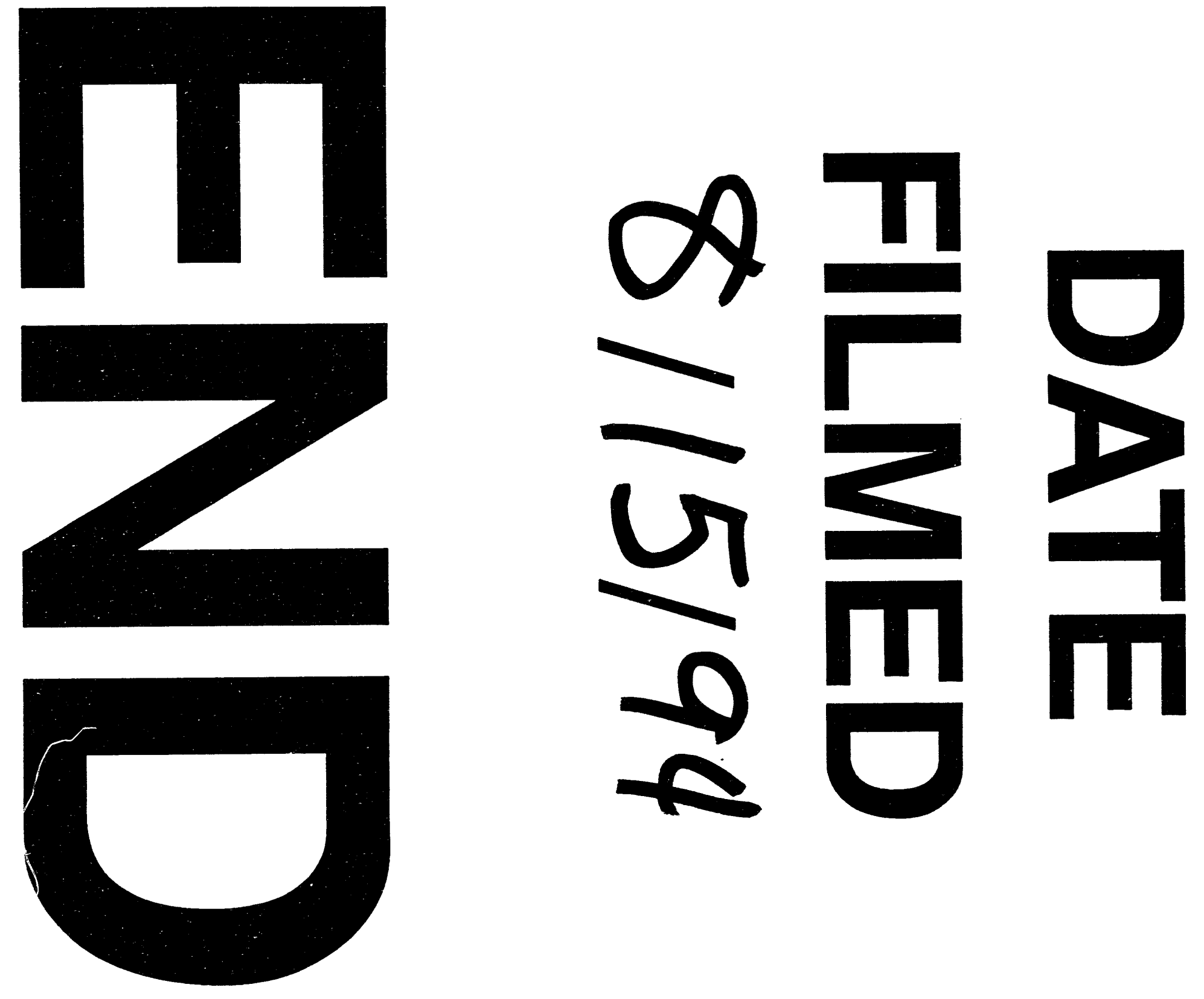
